\title{
Análise ergonômica de um posto da polícia militar de Minas Gerais: Um estudo de
}

\author{
caso \\ Ergonomic analysis of a Military Police post in Minas Gerais: A case study \\ Análisis ergonómico de un puesto de Policía Militar en Minas Gerais: Um estudio de caso
}

Recebido: 25/07/2021 | Revisado: 30/07/2021 | Aceito: 01/08/2021 | Publicado: 06/08/2021

\author{
Dryelle Rodrigues de Freitas \\ ORCID: https://orcid.org/0000-0003-2139-0434 \\ Instituto Federal de Educação, Ciência e Tecnologia de Minas Gerais, Brasil \\ E-mail:dryellerodriguesdefreitas@gmail.com \\ Leandro César Mol Barbosa \\ ORCID: https://orcid.org/0000-0001-7186-5405 \\ Instituto Federal de Educação, Ciência e Tecnologia de Minas Gerais, Brasil \\ E-mail: leandro.mol@ifmg.edu.br
}

\begin{abstract}
Resumo
Grande parte das atividades executadas pelos policiais militares no exercício de sua função tem potencial de expô-los a riscos ergonômicos, danos pessoais e lesões ocupacionais. Além de estarem expostos a uma demanda física desproporcional, os policiais também se encontram sujeitos a tensões que ameaçam seu bem estar psicológico. Esta pesquisa objetiva analisar o espaço de trabalho dos Policiais Militares em um batalhão localizado no interior do estado de Minas Gerais, a fim de propor soluções para os principais pontos de melhoria relacionados à saúde e conforto destes profissionais. Mediante esse cenário, foi realizado um estudo de caso quantitativo e qualitativo. Para tanto foram utilizados como métodos de coleta de dados a realização de entrevistas, bem como o uso dos métodos ergonômicos Rapid Upper Limb Assessment (Rula) e o Questionário Nórdico Musculoesquelético (NMQ), os quais permitiram uma compreensão efetiva do ambiente ao qual esses profissionais estão inseridos e consequentemente o levantamento dos pontos a serem melhorados. Como resultados obtidos, foram verificados pontos importantes de melhoria, tendo sido feitas proposições como o rodizio de turnos em operações, acompanhamento e apoio psicológico dos policiais. Além disso, foi proposta a modificação do layout para reduzir problemas de amplitude de movimentação, assim como a troca ou adaptação de parte do mobiliário e criação de um programa de conscientização para reduzir dores e efeitos adversos do trabalho.
\end{abstract}

Palavras-chave: Ergonomia; Rula; NMQ; Polícia Militar.

\begin{abstract}
A large part of the activities performed by military police officers in the exercise of their function has the potential to expose them to ergonomic risks, personal injuries and occupational injuries. In addition to being exposed to a disproportionate physical demand, police officers also refer to tensions that threaten their psychological well-being. This research aims to analyze the workspace of the Military Police in a battalion located in the interior of the state of Minas Gerais, in order to propose solutions for the main points of improvement related to the health and comfort of these professionals. For this, interviews was used as data collection methods, as well as the use of ergonomic methods Rapid Assessment of the Upper Limb (Rula) and the Nordic Musculoskeletal Questionnaire (NMQ), which allow an effective understanding of the environment to which these inserted professionals and consequently survey of the improved points. As obtained results, important points of improvement were verified, having been made proposals such as the turnover of work shifts in operations, monitoring and psychological support of police officers. In addition, it was proposed to modify the layout to reduce problems with range of movements, as well as to change or adapt part of the furniture and create an awareness program to reduce pain and adverse effects of work.
\end{abstract}

Keywords: Ergonomics; Rula; NMQ; Military Police.

\section{Resumen}

Gran parte de las actividades realizadas por los agentes de la policía militar en el ejercicio de su función tiene el potencial de exponerlos a riesgos ergonómicos, lesiones personales y ocupacionales. Además de estar expuestos a una demanda física desproporcionada, los agentes de policía también están sujetos a tensiones que amenazan su bienestar psicológico. Esta investigación tiene como objetivo analizar el espacio de trabajo de la Policía Militar en un batallón ubicado en el interior del estado de Minas Gerais, con el fin de proponer soluciones para los principales puntos de mejora relacionados con la salud y el confort de estos profesionales. En este escenario, se llevó a cabo un estudio de caso cuantitativo y cualitativo. Para ello, se utilizaron las entrevistas como métodos de recogida de datos, así como el uso de métodos ergonómicos Rapid Upper Limb Assessment (Rula) y el Nordic Musculokeletal Questionnaire 
(NMQ), que permitieron una comprensión eficaz del entorno en el que se insertan estos profesionales. $y$ consecuentemente el relevamiento de los puntos a mejorar. Como resultados obtenidos, se verificaron importantes puntos de mejora, habiéndose formulado propuestas como la rotación de turnos en las operaciones, el seguimiento y apoyo psicológico de los policías. Además, se propuso modificar la distribución para reducir problemas con la amplitud de movimiento, así como cambiar o adaptar parte del mobiliario y crear un programa de sensibilización para reducir el dolor y los efectos adversos del trabajo.

Palabras clave: Ergonomía; Regla; NMQ; Policía Militar.

\section{Introdução}

A utilização de métodos e técnicas ergonômicas visa prover melhorias na relação entre o ambiente de trabalho e o indivíduo. Por meio deles são detectados os anseios e necessidades de mudanças a fim de chegar a resultados que determinem ou melhorem a condição física e psicológica do trabalhador. A ergonomia visa não somente adequar os postos de trabalho, mas também ajustar as atividades laborais com o intuito de propiciar a prevenção de lesões e doenças ocupacionais, bem como melhorar a saúde em geral (Iida, 2005). A postura inadequada, manipulação incorreta de objetos, carga excessiva e longas jornadas podem induzir a doenças e lesões. Isso pode levar a casos crônicos que, quando não tratados adequadamente, podem evoluir para inaptidão parcial ou perda total do movimento e da capacidade de trabalho (Ranney, 2000).

Posto isso, fica claro o risco existente à integridade física dos profissionais militares, estando o policial militar entre aqueles que dispõem de maior risco físico e psicológico no exercício de sua função. Estes riscos, juntamente com o alto rigor da organização, embasada em disciplina e hierarquia, são características rotineiras que o policial militar deve lidar (Minayo \& Adorno, 2013). Tais fatores colocam estes trabalhadores entre as profissões com maior exposição a danos, no que cabe à saúde física e mental (Morais, 2010).

Embora os policiais militares estejam imersos em um ambiente ergonômico complexo, Santos, Souza e Barroso (2017) ressaltam a pouca visibilidade, bem como a baixa compreensão e percepção social quanto aos aspectos referentes à saúde e necessidades destes trabalhadores. De acordo com o Fórum Brasileiro de Segurança Pública (2019), em 2019, 76\% dos policiais foram vítimas de ameaças em decorrência da profissão e $70 \%$ acabaram por ter ao menos um colega morto em serviço. Além disso, estima-se que aproximadamente $25 \%$ dos profissionais militares são afastados ao ano devido a problemas psicológicos ou físicos, sendo que anualmente um a cada três agentes acabam por ficar de licença médica em consequência de transtornos resultantes da profissão (Associação dos Praças Policiais e Bombeiros Militares de Minas Gerais, 2019). Tais condições revelam um ambiente de trabalho o qual, conforme Anchieta, Galinkin, Mendes e Neiva (2011), está imerso em condições insalubres. Estas condições, por sua vez, acarretam doenças ocupacionais que podem se agravar devido a precarização e ao desarranjo do trabalho.

Baseado no exposto, para compreender as reais condições de vida e de trabalho destes profissionais, faz-se importante entender os problemas relacionados às suas funções. Este entendimento deve ser aprofundado e detalhado por meio da perspectiva dos próprios trabalhadores. Dessa forma, o presente estudo busca colaborar com a melhoria contínua da qualidade do trabalho dos policiais militares de forma a possibilitar a redução dos riscos de doenças ocupacionais. Para isso, foi realizado um estudo de caso em um batalhão da Polícia Militar localizado em uma cidade do interior de Minas Gerais no intuito de levantar pontos de atenção e propostas de melhoria.

O estudo de caso contou com a utilização combinada de três técnicas de levantamento de dados, sendo elas o questionário Nórdico, o método Rapid Upper Limb Assessment (RULA) e a realização de entrevistas. As três técnicas foram utilizadas em conjunto de forma que tanto fatores físicos quanto cognitivos pudessem ser considerados.

O artigo encontra-se estruturado da seguinte forma: no tópico 2 foi abordada a revisão teórica com discussões introdutórias sobre ergonomia e os métodos ergonômicos utilizados durante a pesquisa; no tópico 3 foram descritos e analisados os métodos a serem utilizados para a realização do estudo, bem como a estrutura e o desenvolvimento da pesquisa; 
no tópico 4 foi feita a apresentação dos resultados, os quais foram discutidos no tópico 5 em função da literatura, de forma a identificar proposições de melhorias ergonômicas. Por fim, no tópico 6 foram realizadas as considerações finais do trabalho, em que serão expostos os achados de pesquisa, limitações e indicações de trabalhos futuros.

\section{Referencial Teórico}

A polícia Militar é a área da administração pública incumbida da execução do controle social e preservação da segurança pública (Brasil, 1988). A importância da polícia militar para a sociedade está ligada à sua atuação na linha de frente do combate à criminalidade e da proteção do cidadão. Para tanto, possui uma organização que valoriza a hierarquia, bem como a disciplina de seus membros, os quais estão sujeitos a rotinas rigorosas de trabalho (Minayo \& Adorno, 2013).

A jornada do policial militar exige muitas vezes a aplicação de força física além do aconselhável em análises laborais, treinos intensos e tensão psicológica. Em escritório, problemas relacionados à postura e movimentos repetitivos também podem ser observados. Isso faz com que o trabalho do policial militar seja marcado por um dualismo de fatos ergonômicos, tanto nas questões cognitivas, quanto físicas (Maria, Santana, Freitas, Gomes \& Barbosa, 2019).

Uma vez exposto a longas jornadas de trabalho em pé, assim como ao uso de aparatos pesados até mesmo durante corridas, é evidente a importância da forma física e da saúde psicológica (Rodriguez, 2003). Além disso, a precarização de seus equipamentos e as condições salariais incompatíveis, os coloca entre os profissionais com maior risco a desenvolver doenças ocupacionais (Silva \& Vieira, 2008). Isso abre campo para a realização de estudos ergonômicos que visem a melhoria de suas condições de trabalho.

\subsection{Aspectos da atuação ergonômica}

A ergonomia é o campo de estudo que engloba conhecimentos para criação de objetos e meios que possibilitem uma maior segurança, conforto e eficácia (Minicucci, 1995). Essa dispõe sobre percepções referentes à antropometria, psicologia, sociologia e fisiologia (Wisner, 1987), com o propósito empregar conhecimento científico na adequação dos recursos tecnológicos e do ambiente (Rio \& Pires, 2001). Quando aplicada ao trabalho, auxilia na redução de doenças ocupacionais e imprime uma maior satisfação do homem com seu ambiente laboral (Iida, 2005; Michel, 2000). Esta é feita por meio de uma interpelação holística do trabalho, em que se observa seus aspectos do ponto de vista da ergonomia física, cognitiva e organizacional (Vidal, 2002), com o objetivo de estabelecer regras que beneficiem tanto o trabalhador quanto a empresa (Sampaio \& Batista, 2021).

A ergonomia física trata de assuntos ligados à biomecânica, antropometria, fisiologia (Vidal, 2002), abordando questões como lesões por esforço repetitivo, segurança nos postos de trabalho e distúrbios musculoesqueléticos (lida, 2005). Por meio dela é realizada a análise das reações do corpo humano frente às condições em que é submetido (Rangel, 2010). A ergonomia cognitiva refere-se a todos os aspectos do trabalho que estão ligados à mente e ao psicológico dos indivíduos (Vidal, 2002). Essa está associada a todo o meio de percepção, processamento de informações, resposta e relacionamento humano no desempenho das atividades (Iida, 2005; Bitencout, Guimarães \& Saurin, 2004). Já a ergonomia organizacional trata de todas as questões associadas à melhoria das estruturas do trabalho (Vidal, 2002) e leva em consideração o aprimoramento das estruturas e das políticas internas da organização (Associação Brasileira de Ergonomia, 2000).

Quanto às formas de atuação, a ergonomia pode ser subdividida em dois tipos: a ergonomia de correção e a ergonomia de concepção. A ergonomia de correção consiste no aprimoramento das conjunturas do trabalho, mesmo que muitas vezes aconteça de forma parcial e com eficiência limitada. Esse tipo de ergonomia tem como fundamento o reparo do ambiente no qual as atividades acontecem por meio de intervenções (Abrantes, 2004). Já a ergonomia de concepção atua na elaboração do ambiente ou produto, definindo em seu projeto as características ergonômicas (Barros, 1996). Um terceiro tipo de ergonomia, 
denominado como ergonomia de conscientização ainda pode ser observado. Esse visa a difusão do conhecimento ergonômico e sua percepção pelos trabalhadores por meio da capacitação (Abrantes, 2004; Baú, 2002).

No Brasil, a busca pela regulamentação da ergonomia e de seus métodos de intervenção se deu por meio do estabelecimento das Normas Regulamentadoras (NRs) em 1978. Dentre elas, destaca-se a NR-17 que determina parâmetros para adequar os ambientes organizacionais aos trabalhadores, além de colocar as empresas como as responsáveis pela realização da Análise Ergonômica do Trabalho (AET) (Oliveira \& Oliveira, 2020). A AET simboliza uma ruptura da forma como eram abordados os métodos e teorias ergonômicas até então, propiciando uma forma de atuação em que o trabalho é o principal agente do estudo. Por meio da NR17, as empresas ficam responsáveis por propiciar as condições mínimas de trabalho relacionadas à saúde física e mental de seus funcionários (Silveira, Cezar-Vaz, \& Xavier, 2020).

\subsection{Análise Ergonômica do Trabalho}

A Análise Ergonômica do Trabalho (AET) é um método participativo que visa solucionar uma adversidade por meio do conhecimento da atividade e de seus problemas, de maneira a alcançar a produtividade desejada (Vieira, 2014). Tal método é considerado por Bouyer (2007) como um grande passo a caminho da maturidade da ergonomia como uma ciência. Isso porquê a AET originou uma nova forma de se pensar sobre o que constitui o estudo do ambiente de trabalho, em que a atividade do trabalhador é colocada com a ênfase necessária.

Para Guérin, Kerguelen e Laville (2001) toda a ação ergonômica ocorre por meio de uma necessidade proveniente da insatisfação dos indivíduos. Assim a AET promove transformações que possibilitam a realização de atividades de maneira que a saúde dos trabalhadores não seja afetada e que os lucros empresariais consigam atingir seus objetivos, o que abre várias possibilidades de análise. Dentre elas, Alves (2003) destaca o exame da durabilidade da jornada de trabalho, da incumbência do trabalhador, do esforço muscular, das posturas, das máquinas ou dos meios usados ao decorrer da função. Além disso, a Análise Ergonômica do Trabalho ainda possibilita a verificação das adequações das instalações de acordo com cada indivíduo, estabelecendo as principais causas que possam vir a gerar sobrecarga de trabalho (Abrantes, 2004).

Em sua aplicação, a AET é composta por três etapas de análise: a análise da demanda, da tarefa e das atividades. Na primeira é estabelecida a situação problema a ser estudada juntamente com os agentes envolvidos (Santos \& Fialho, 1997). Mascia e Sznelwar (1997) afirmam que a análise de demanda é fundamental para o entendimento adequado da situação problema e da proporção dela, estando diretamente ligada a compreensão e sugestão de alterações com a finalidade de solucionar o problema levantado. Na segunda, a análise da tarefa, é verificado o que é designado ao trabalhador e quais são as conjunturas técnicas e organizacionais às quais ele será submetido (Santos \& Fialho, 1997). Esta etapa é importante pois possibilita a visualização das diferenças entre o que é executado e o que é prescrito pelas empresas (Mascia \& Sznelwar, 1997). Já na análise das atividades, é relatado o que de fato o colaborador executa, bem como seu comportamento frente ao trabalho (Santos \& Fialho, 1997). Nesta etapa a observação das ações dos trabalhadores é determinante para a percepção e justificativa de seus atos (Mascia \& Sznelwar, 1997).

Santos e Santos (2006), destacam que além das três etapas de análise a AET ainda possui a etapa de diagnóstico e recomendação. A etapa de diagnóstico refere-se a reconhecer os fatores de risco para as organizações e o eventual grau desses riscos, bem como as chances de desenvolver doenças oriundas da função nos trabalhadores. Já quanto à recomendação, os autores afirmam que essa é a etapa em que são expostas as modificações com o intuito de sanar os problemas anteriormente diagnosticados, bem como dar prosseguimento nas atividades que estão em conformidade com as regras ergonômicas.

A utilização destes procedimentos faz com que a AET possua uma estrutura clara e fácil quando se trata da constatação, análise e ação frente a situação problema. Além disso, permite com que ela atue sobre a multiplicidade das ações 
em função dos componentes que impactam diretamente o trabalho, podendo levar em consideração características tanto físicas como ambientais (Deimling \& Pesamosca, 2014).

Para tanto, a AET se utiliza de outras disciplinas, métodos e ferramentas com o intuito de obter dados mais assertivos no tocante à análise das funções laborais. De acordo com Oliveira e Mont’alvão (2015), os métodos e ferramentas ergonômicas permitem avaliar a viabilidade e usabilidade de produtos e postos de trabalho. Dentre esses, pode-se destacar o método RULA e o Questionário Nórdico, tratados nos tópicos seguintes.

\subsection{Rula}

O Método Rapid Upper Limb Assessment (RULA) foi concebido por Lynn McAtamney e E. Nigel Corlett em 1993 e busca avaliar a exposição dos indivíduos a posturas que possam resultar em distúrbios (Stanton, Brookhuis, Salas \& Hendrick, 2004). Embora o método dê ênfase aos riscos de disfunções ligadas à postura, utilização excessiva da força e funções com esforços repetitivos nos membros superiores, o método não exclui os membros inferiores, sendo estes uma parte importante da análise (Baú, 2002; Lueder, 1996).

A sua aplicação tem como objetivo principal permitir uma verificação da exposição de funcionários a fatores de riscos que possam vir a gerar lesões musculoesqueléticas durante as atividades dos mesmos (Junior, 2009; Shida \& Bento, 2012). Uma das vantagens de sua utilização é a avaliação rápida de danos potenciais nos membros superiores (Mcatamney \& Corlett, 1993).

O início da aplicação do RULA se dá por meio da observação das funções desempenhadas no decorrer dos ciclos de trabalho (Shida \& Bento, 2012). Após adquirir os dados através do estudo direto e indireto, ou seja, por meio da coleta de dados sem e com a intervenção do alvo analisado, a análise é feita levando em consideração a força exercida, a postura utilizada e os movimentos relacionados às atividades dos trabalhadores (Stanton, Brookhuis, Salas \& Hendrick, 2004)

É empregado um esquema de análise postural e corporal por meio de uma tabela de pontuação que viabiliza a análise da exposição dos funcionários às condições de risco (Junnior, Silva \& Canedo, 2017).

De acordo com McAtamney e Corlett (1993) as posturas do RULA são estabelecidas com base no ângulo entre o corpo e os membros, sendo divididos em dois grupos: grupo A e grupo B. O grupo A é composto pelos braços, antebraços e punhos conforme Figura 1, enquanto o grupo B é formado pelo pescoço, tronco, pernas e pés como observado na Figura 2. 
Figura 1: Diagrama de Postura do Grupo A.

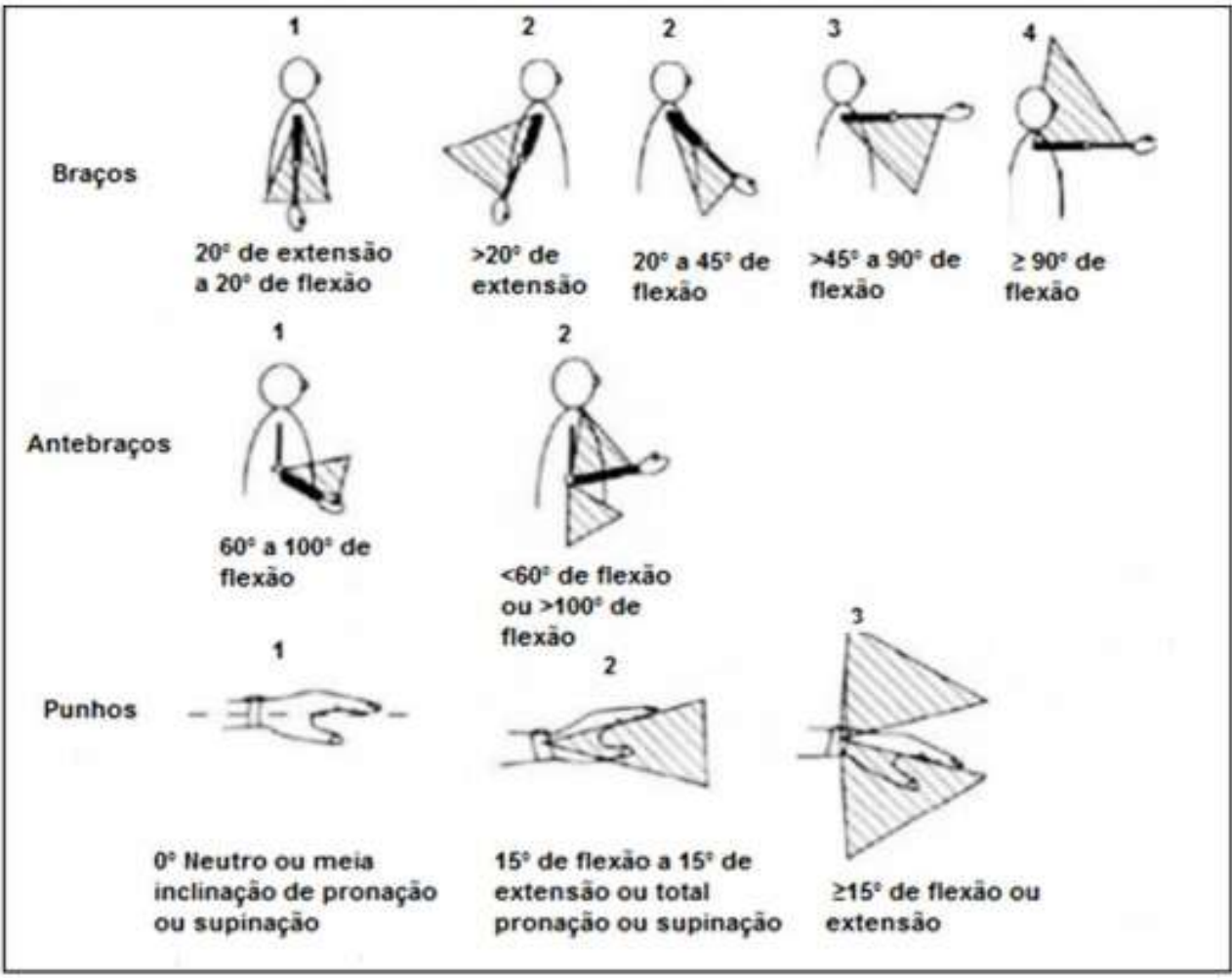

Fonte: Adaptada de Mcatamney \& Corllet (1993).

Figura 2: Diagrama de Postura do Grupo B

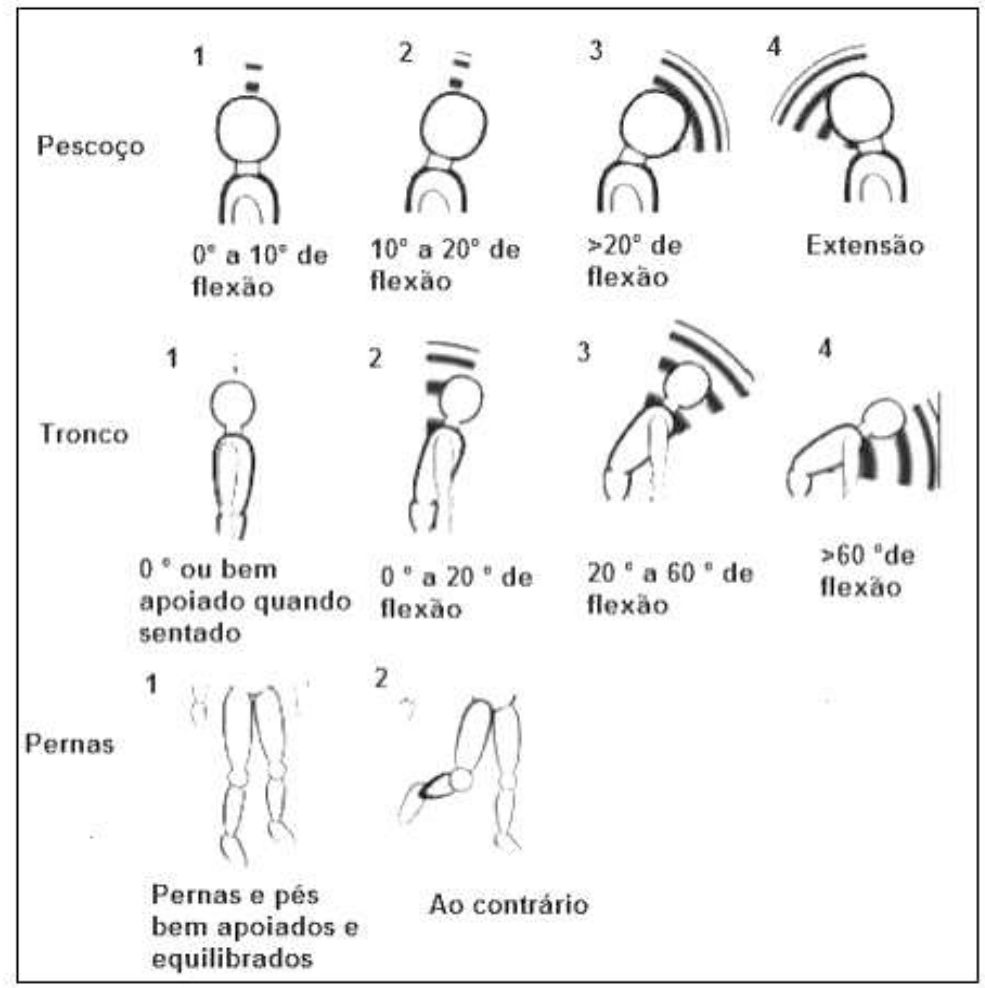

Fonte: Adaptada de Mcatamney \& Corllet (1993). 
No decorrer da avaliação dos grupos, as posturas adotadas podem atingir uma pontuação entre 1 e 4, conforme Figuras 1 e 2. Ao somar os ajustes e peso de cada uma das situações, a pontuação pode chegar a 7. A combinação das pontuações para o Grupo A pode ser vista na Tabela 1, considerando os ângulos do braço, antebraço e pulso.

Tabela 1: Combinação de pontuações do Grupo A.

\begin{tabular}{|c|c|c|c|c|c|c|c|c|c|}
\hline \multirow{4}{*}{ Braço } & \multirow{4}{*}{ Antebraço } & \multicolumn{8}{|c|}{ Total da Postura do Pulso } \\
\hline & & & & & & & & & \\
\hline & & \multicolumn{2}{|c|}{ Torcão Pulso } & \multicolumn{2}{|c|}{ Torcão Pulso } & \multicolumn{2}{|c|}{ Torcâo Pulso } & \multicolumn{2}{|c|}{ Torcaio Pulso } \\
\hline & & 1 & 2 & 1 & 2 & 1 & 2 & 1 & 2 \\
\hline \multirow{3}{*}{1} & 1 & 1 & 2 & 2 & 2 & 2 & 3 & 3 & 3 \\
\hline & 2 & 2 & 2 & 2 & 2 & 3 & 3 & 3 & 3 \\
\hline & 3 & 2 & 3 & 3 & 3 & 3 & 3 & 4 & 4 \\
\hline \multirow{3}{*}{2} & $\mathrm{I}$ & 2 & 3 & 3 & 3 & 3 & 4 & 4 & 4 \\
\hline & 2 & 3 & 3 & 3 & 3 & 3 & 4 & 4 & 4 \\
\hline & 3 & 3 & 4 & 4 & 4 & 4 & 4 & 5 & 5 \\
\hline \multirow{3}{*}{3} & 1 & 3 & 3 & 4 & 4 & 4 & 4 & 5 & 5 \\
\hline & 2 & 3 & 4 & 4 & 4 & 4 & 4 & 5 & 5 \\
\hline & 3 & 4 & 4 & 4 & 4 & 4 & 5 & 5 & 5 \\
\hline \multirow{3}{*}{4} & $\mathrm{I}$ & 4 & 4 & 4 & 4 & 4 & 5 & 5 & 5 \\
\hline & 2 & 4 & 4 & 4 & 4 & 4 & 5 & 5 & 5 \\
\hline & 3 & 4 & 4 & 4 & 5 & 5 & 5 & 6 & 6 \\
\hline \multirow{3}{*}{5} & $T$ & 5 & 5 & 5 & 5 & 5 & 6 & 6 & 7 \\
\hline & 2 & 5 & 6 & 6 & 6 & 6 & 7 & 7 & 7 \\
\hline & 3 & 6 & 6 & 6 & 7 & 7 & 7 & 7 & 8 \\
\hline \multirow{3}{*}{6} & $T$ & 7 & 7 & 7 & 7 & 7 & 8 & 8 & 9 \\
\hline & 2 & 8 & 8 & 8 & 8 & 8 & 9 & 9 & 9 \\
\hline & 3 & 9 & 9 & 9 & 9 & 9 & 9 & 9 & 9 \\
\hline
\end{tabular}

Fonte: Adaptada de Mcatamney \& Corllet (1993).

A combinação das pontuações para o Grupo B está disposta na Tabela 2, considerando os ângulos do pescoço, tronco e pernas.

Tabela 2: Quadro Total do Grupo B

\begin{tabular}{|c|c|c|c|c|c|c|c|c|c|c|c|c|}
\hline \multirow{4}{*}{$\begin{array}{l}\text { Score da } \\
\text { Postura do } \\
\text { Pescoço }\end{array}$} & \multicolumn{12}{|c|}{ Score da Postura do Tronco } \\
\hline & \multicolumn{2}{|c|}{1} & \multicolumn{2}{|c|}{2} & \multicolumn{2}{|c|}{3} & \multicolumn{2}{|c|}{4} & \multicolumn{2}{|c|}{5} & \multicolumn{2}{|c|}{6} \\
\hline & \multicolumn{2}{|c|}{ Pernas } & \multicolumn{2}{|c|}{ Pernas } & \multicolumn{2}{|c|}{ Pernas } & \multicolumn{2}{|c|}{ Pernas } & \multicolumn{2}{|c|}{ Pernas } & \multicolumn{2}{|c|}{ Pernas } \\
\hline & 1 & 2 & 1 & 2 & 1 & 2 & 1 & 2 & 1 & 2 & 1 & 2 \\
\hline 1 & 1 & 3 & 2 & 3 & 3 & 4 & 5 & 5 & 6 & 6 & 7 & 7 \\
\hline 2 & 2 & 3 & 2 & 3 & 4 & 5 & 5 & 5 & 6 & 7 & 7 & 7 \\
\hline 3 & 3 & 3 & 3 & 4 & 4 & 5 & 5 & 6 & 6 & 7 & 7 & 7 \\
\hline 4 & 5 & 5 & 5 & 6 & 6 & 7 & 7 & 7 & 7 & 7 & 8 & 8 \\
\hline 5 & 7 & 7 & 7 & 7 & 7 & 8 & 8 & 8 & 8 & 8 & 8 & 8 \\
\hline 6 & 8 & 8 & 8 & 8 & 8 & 8 & 8 & 9 & 9 & 9 & 9 & 9 \\
\hline
\end{tabular}

Fonte: Adaptada de Mcatamney \& Corllet, (1993).

Após a obter dos valores do grupo A e B, são analisados o uso dos músculos e a força suportada. Para o músculo, caso haja uma postura com predominância estática por mais de 60 segundos ou uma ação repetitiva por até 4 minutos, deve ser acrescido o valor de 1 ponto no grupo A ou no grupo B, conforme observação. Já para a força suportada, são utilizados o valor das cargas da seguinte maneira: se o peso for menor do que $2 \mathrm{~kg}$ e for usada de forma intermitente, não são acrescidos pontos; se a carga estiver entre $2 \mathrm{~kg}$ e $10 \mathrm{~kg}$ e sua utilização se der de forma intermitente, deve ser imputado mais 1 ponto a postura; se as cargas estiverem entre $2 \mathrm{~kg}$ e $10 \mathrm{~kg}$ e forem usadas de forma estática ou repetitiva, deve-se atribuir mais 2 pontos; já se a 
carga estiver acima de $10 \mathrm{~kg}$ e for utilizada de maneira repetitiva ou possuir um alto impacto, devem ser atribuídos 3 pontos à postura analisada.

Os dados obtidos do grupo A e B são combinados em uma terceira tabela para a obtenção da pontuação final. Quanto maior a pontuação obtida, maior a necessidade de uma intervenção ergonômica no local ou ações imediatas (Mcatamney \& Corllet, 1993.).

Tabela 3: Pontuação final.

\begin{tabular}{|c|c|c|c|c|c|c|c|}
\hline & \multicolumn{7}{|c|}{ Grupo B } \\
\hline Grupo A & 1 & 2 & 3 & 4 & 5 & 6 & $7+$ \\
\hline 1 & 1 & 2 & 3 & 3 & 4 & 5 & 5 \\
\hline 2 & 2 & 2 & 3 & 4 & 4 & 5 & 5 \\
\hline 3 & 3 & 3 & 3 & 4 & 4 & 5 & 6 \\
\hline 4 & 3 & 3 & 3 & 4 & 5 & 6 & 6 \\
\hline 5 & 4 & 4 & 4 & 5 & 6 & 7 & 7 \\
\hline 6 & 4 & 4 & 4 & 5 & 6 & 7 & 7 \\
\hline 7 & 5 & 5 & 6 & 6 & 7 & 7 & 7 \\
\hline $8+$ & 5 & 5 & 6 & 7 & 7 & 7 & 7 \\
\hline 1 ou 2 & \multicolumn{3}{|c|}{ Postura aceitável por períodos curtos } & 5 ou 6 & \multicolumn{3}{|c|}{$\begin{array}{l}\text { Necessita investigação. Mudança } \\
\text { rápida necessária. }\end{array}$} \\
\hline 3 ou 4 & \multicolumn{3}{|c|}{$\begin{array}{l}\text { Necessita investigação. Possível } \\
\text { mudança requerida. }\end{array}$} & $\begin{array}{l}\text { Igual ou } \\
\text { maior a } 7\end{array}$ & \multicolumn{3}{|c|}{$\begin{array}{l}\text { Necessita investigação. Mudança } \\
\text { imediata. }\end{array}$} \\
\hline
\end{tabular}

Fonte: Adaptada de Mcatamney \& Corllet (1993).

\subsection{Questionário Nórdico}

O Questionário Nórdico Musculoesquelético (NMQ) é uma das principais ferramentas ergonômicas utilizadas para a análise de sintomas relacionados aos músculos, estruturas ósseas e para a saúde e segurança ocupacional do trabalhador de forma geral. Esta ferramenta facilita a determinação dos sintomas pelos trabalhadores, bem como torna mais explícita a necessidade de busca por recursos de saúde (Ferrari, 2009).

Para Pinheiro, Tróccole e Carvalho (2002), o propósito do NMQ é padronizar os parâmetros e informações de sintomas osteomusculares, promovendo a analogia entre estudos em que há aplicação do método. A utilização do questionário não possui indicação para diagnósticos clínicos, uma vez que tal ferramenta auxilia apenas na sinalização de distúrbios osteomusculares e diagnósticos de postos de trabalho.

De acordo com Iida (2005) o NQM deve ser utilizado como um mapa corporal no qual o corpo humano é dividido em nove partes. $\mathrm{O}$ colaborador assinala com sim ou não perguntas referentes a estas nove partes visando compreender quais delas apresentam maior incômodo para ele (Ferrari, 2009). Estes devem ser questionados sobre o período de um ano de trabalho, sobre a semana anterior ao questionário, bem como sobre a ocorrência ou não de afastamento das atividades exercidas. Um exemplo de questionário pode ser verificado na Figura 3. 
Figura 3: Documento utilizado na ferramenta NMQ.

\begin{tabular}{|c|c|c|c|c|c|c|}
\hline & & & \multicolumn{4}{|c|}{$\begin{array}{l}\text { Questionário Nórdico } \\
\text { dos sintomas } \\
\text { músculo-esquelético }\end{array}$} \\
\hline \multirow{2}{*}{\multicolumn{3}{|c|}{ (2) $=$}} & \multicolumn{4}{|c|}{$\begin{array}{l}\text { Marque um }(x) \text { na resposta apropriada. Marque apenas um }(x) \\
\text { para cada queståo. } \\
\text { Näo, indica conforto, saude - Sim, indica incómodos, descon- } \\
\text { fortos, dores nessa parte do corpo. }\end{array}$} \\
\hline & & & \multicolumn{4}{|c|}{$\begin{array}{l}\text { ATENÇĀO: O desenho ao lado representa apenas uma posiçăo } \\
\text { aproximada das partes do corpo. Assinale a parte que mais se } \\
\text { proxima do seu problema }\end{array}$} \\
\hline $\begin{array}{l}\text { Partes do corpo } \\
\text { com problemas }\end{array}$ & \multicolumn{2}{|c|}{$\begin{array}{c}\text { Vocè teve algum problema } \\
\text { nos ultimos } 7 \text { dlas? }\end{array}$} & \multicolumn{2}{|c|}{$\begin{array}{l}\text { Vocè teve algum problema } \\
\text { nos ultimos } 12 \text { meses? }\end{array}$} & \multicolumn{2}{|c|}{$\begin{array}{l}\text { Você teve que deficar de trabar } \\
\text { Thar algum dila nos ultimos } 12 \\
\text { meses devido ao problema? }\end{array}$} \\
\hline 1-Pescoso & 1 D Na & $20 \mathrm{Sim}$ & 10 NJo & $20 \mathrm{Sim}$ & 1 CNdo & $20 \mathrm{Sim}$ \\
\hline 2-Ombros & $\begin{array}{l}1 \square \text { NSo } \\
2 \square \operatorname{Sim}-\text { om } \\
3 \square \operatorname{Sim}-\text { om } \\
4 \square \operatorname{Sim}-\operatorname{os}\end{array}$ & $\begin{array}{l}\text { direito } \\
\text { asquerdo } \\
\text { ombros }\end{array}$ & $\begin{array}{l}1 \square \text { Nà } \\
2 \square \operatorname{Sim}=0 \mathrm{~m} \\
3 \square \operatorname{Sim}=\text { om } \\
4 \square \operatorname{Sim}=0 \mathrm{c}\end{array}$ & $\begin{array}{l}\text { direito } \\
\text { esquerdo } \\
\text { ombros }\end{array}$ & 10 Nào & $2 \square \mathrm{Sim}$ \\
\hline 3-Cotovelos & $\begin{array}{l}1 \square \text { Naio } \\
2 \square \operatorname{Sim}-\cot \\
3 \square \operatorname{Sim}-\cot \\
4 \square \operatorname{Sim}-\operatorname{os} c\end{array}$ & $\begin{array}{l}\text { direito } \\
\text { esquerdo } \\
\text { cotovelos }\end{array}$ & $\begin{array}{l}1 \square \text { NSo } \\
2 \square \mathrm{Sim} \cdot \cot 0 \\
3 \square \mathrm{Sim} \cdot \cot \\
4 \square \mathrm{Sim} \cdot \mathrm{os}\end{array}$ & $\begin{array}{l}\text { direito } \\
\text { esquerdo } \\
\text { cotovelos }\end{array}$ & 1 Nào & $2 \square \mathrm{Sim}$ \\
\hline 4-Punhos e màos. & $\begin{array}{l}1 \square \text { Na } \\
2 \square S i m \text { - pur } \\
3 \square S i m \text { - pur } \\
4 \square S i m \text { - os }\end{array}$ & $\begin{array}{l}\text { nâo direita } \\
\text { nào esquerda } \\
\text { punhoimdo }\end{array}$ & $\begin{array}{l}1 \square \text { Nào } \\
2 \square S i m \text { - pun } \\
3 \square S i m \text { - pun } \\
4 \square S i m \text { - os d }\end{array}$ & $\begin{array}{l}\text { nào direita } \\
\text { nذ̀ esquerda } \\
\text { punho/mذ̌ }\end{array}$ & & \\
\hline 5-Coluna dorsal & 1 N Nào & $20 \operatorname{sim}$ & 1 Nato & $20 \operatorname{sim}$ & 1 [Nào & $205 \mathrm{im}$ \\
\hline 6-Coluna lombar & 10 NBo & $205 i m$ & 10 Nào & $205 \mathrm{im}$ & $10 \mathrm{NBo}$ & $205 \mathrm{im}$ \\
\hline 7. Quadnil ou coxas & 10 NSo & $2 \square \mathrm{Sim}$ & $1 \square$ NSo & $20 \mathrm{Sim}$ & $1 \square$ NAo & $20 \mathrm{Sim}$ \\
\hline 8-Joelhos & 1 CNbo & $205 i m$ & 1 Nào & $20 \operatorname{sim}$ & $10 \mathrm{NBo}$ & $2 \square 5 i m$ \\
\hline 9-Tomozelo ou pes & 1 NAo & $205 \mathrm{sim}$ & 10 MSo & $20 \mathrm{Sim}$ & 10 N3o & $20 \mathrm{sim}$ \\
\hline
\end{tabular}

Fonte: Iida (2005).

No Brasil tal metodologia foi sugerida por Barros e Alexandre (2003) e desde então os mais variados estudos foram executados, sendo verificados bons resultados no geral. Por exemplo: Prufer et al (2013) em seus estudos sobre Distúrbios Osteomusculares Relacionados ao Trabalho (DORT), destaca que programas embasados no NMQ obtiveram um impacto positivo na redução de sintomas e dores através da fisioterapia preventiva; Afonso, Pinho e Arezes (2014), ao aplicarem o NMQ junto a costureiras em uma empresa de calçados, destacou a obtenção de um maior foco sobre os fatores de riscos assinalados, tornando possível verificar as necessidades e realizar a implementação de programas ergonômicos de prevenção; Lemos (2009), ao fazer uso do NQM em motoristas de caminhão com jornadas irregulares, pôde estabelecer uma relação entre as queixas de dores com a falta de descanso e qualidade no sono; Já Pinheiro, Tróccoli e Carvalho (2002), após fazerem uso do NQM, concluiu que esse não somente apresenta bons índices de validação, como também indica seu uso como meio de mensurar a morbidade osteomuscular. 


\section{Metodologia}

O artigo tem como objeto de estudo um batalhão da Polícia Militar de Minas Gerais. Tal instituição foi escolhida dada a sua importância para a sociedade na atuação da linha de frente do combate à criminalidade e a proteção do cidadão, assim como pelas questões ergonômicas envolvidas na sua atividade. Anchieta, Galinkin, Mendes e Neiva (2011), evidenciam que os profissionais militares estão inseridos em ambientes insalubres e que tais ambientes, podem levar a doenças ocupacionais, estas agravadas em decorrência da precarização do ambiente de trabalho.

Em relação ao método, optou-se pela realização de um estudo de caso descritivo. A escolha desse método teve como finalidade entender o evento estudado de forma abrangente e aprofundada (Yin, 2015), com foco na real situação vivenciada pelos policiais militares no exercício de sua função. Dessa forma, esse estudo visa descrever a influência dos postos de trabalho e atividades da corporação estudada sobre os policiais.

A abordagem utilizada foi qualitativa e quantitativa. Enquanto qualitativa, propiciou uma maior profundidade tanto nas relações do trabalhador com o ambiente, como uma melhor percepção dos fenômenos presentes na rotina dos policiais militares (Minayo, 2001). Enquanto quantitativa, a utilização de meios de análise numérica e estatísticas (Collins \& Hussey, 2005) propiciaram um melhor enquadramento, inclusive por meio das análises gráficas.

O processo de coleta de dados foi feito por meio da aplicação do Questionário Nórdico e do método RULA, com o objetivo de investigar as condições ergonômicas nos postos de trabalho. A ferramenta RULA foi escolhida devido a sua fácil aplicação e agilidade em reconhecer as atividades que possam apresentar riscos (Mcatamney \& Corllet,1993). Já o questionário Nórdico foi selecionado visto que facilita a determinação dos sintomas pela ótica dos trabalhadores, bem como torna mais explícita a necessidade de busca por recursos de saúde (Iida, 2005). Esse foi direcionado a 4 profissionais que trabalham em escritório, realizando atividades administrativas.

A coleta de dados também contou com entrevistas semiestruturadas com 7 integrantes do batalhão. Estas foram realizadas com o intuito de obter informações mais detalhadas sobre as rotinas de trabalho e queixas dos policiais. No Quadro 1 são apresentadas informações sobre as entrevistas.

Quadro 1: Informações dos entrevistados

\begin{tabular}{|c|c|c|c|c|c|}
\hline Cargo & Sexo & Idade & Grau de intrução & Tempo De serviço & Duração das entrevistas \\
\hline Comandante Regional & Masculino & 49 & Pós-Graduação & 28 & $31: 10: 03$ \\
\hline Comandante de Guarnição & Masculino & 54 & Pós-Graduação & 30 & $35: 07: 20$ \\
\hline Cabo 1 & Femininino & 33 & Superior completo & 11 & $39: 18: 03$ \\
\hline Cabo 2 & Masculino & 42 & Superior Incompelto & 17 & $29: 55: 19$ \\
\hline Sargento 1 & Femininino & 55 & Superior Completo & 26 & $38: 03: 01$ \\
\hline Sargento 2 & Masculino & 44 & Superior Completo & 15 & $37: 04: 26$ \\
\hline Soldado & Masculino & 32 & Superior Completo & 5 & $32: 15: 00$ \\
\hline
\end{tabular}

Fonte: Autores.

Coletados os dados, esses foram tratados e tabulados visando buscar os pontos de maior atenção com relação à rotina de trabalho e ao ambiente em que são executados. Os resultados foram apresentados e depois discutidos em função da literatura. Foram então propostas alterações relacionadas às rotinas, ao ambiente de trabalho e às tarefas executadas pelos policiais. A partir disso foram traçadas as considerações finais sobre os resultados obtidos, assim como sugestões de trabalhos futuros.

\section{Análise e Apresentação dos Resultados}

A análise da jornada de trabalho dos policiais, mostrou que as horas de trabalho diárias podem ser elevadas e estafantes. De acordo com as entrevistas realizadas, foi possível verificar que a necessidade de cumprimento de turnos maiores 
que 8 horas não é uma exceção. A maioria dos entrevistados cumprem turnos ocasionais de 12 horas, sendo que, na ocorrência de emergências, esse turno pode aumentar. Nestes casos, não é possível prever uma duração específica, havendo relatos de turno de até mais de 16 horas. Dois depoimentos auferidos das entrevistas relatam tal imprevisibilidade:

"Tecnicamente a carga horaria é de 40 horas semanais, mas depende muito da escala e do que vai acontecer durante o dia. Já tive turnos de 16 horas, sem almoçar, acaba que na rotina de um policial a única hora que temos certeza é a de inicio do trabalho" (Comandante da Guarnição)

“(...) nesses mais de 20 anos de corporação poucas foram as vezes em que eu cumpri menos do que 10 horas de turno." (Sargento 1)

Com relação à disposição para o trabalho, todos os entrevistados se consideraram aptos ao exercício de suas funções. Porém, apenas um dos entrevistados relatou não sentir nenhuma dor ou incomodo no posto de trabalho. Todos os outros entrevistados relataram diferentes tipos de problema, em especial dores na coluna cervical, na lombar e nos punhos.

Das funções exercidas, a que mais gerou queixas de desconforto foram as funções administrativas. Dentre elas está o preenchimento de boletim de ocorrência e análise de documentação interna. Além das dores, foram relatadas queixas ligadas ao ambiente de trabalho, principalmente com relação a iluminação, as longas horas em frente ao computador e ao ruído interno. Em seguida, as queixas se concentraram na área operacional, na qual os principais relatos estão ligados às longas horas de trabalho em pé ou dirigindo. Tais funções foram relatadas como desconfortáveis tanto pela pressão e sensação de estresse como pelo esforço físico causado pelo ambiente. Outras questões relatadas incluem o ruído do trânsito e o desconforto com a vestimenta.

"Estresse e pressão são coisas comuns no nosso dia a dia. Eu saio de casa sem saber se vou voltar. Pra você ter uma ideia, já tive que correr atrás de meliantes mata a dentro depois de ter dormido 4 horas, sem comer e sem visão clara do perímetro por motivos óbvios." (Soldado)

Cabe salientar que todos os entrevistados relataram o estresse como um fator comum no trabalho devido a situações de conflito oriundas da profissão. Dentre as causas do estresse, 4 dos 7 entrevistados as relacionam com ocorrências graves ao longo da jornada de trabalho. Estas envolvem alta periculosidade e risco de confronto. Já para 2 entrevistados, problemas como insônia ou excesso de sono durante o expediente de trabalho são os grandes responsáveis por esse desconforto e para 1 dos entrevistados acaba por ser uma combinação de longos turnos, com poucas horas de sono e grande número de ocorrências. Tais circunstâncias ficam claras no depoimento do soldado.

“(...) muitas vezes acordo assustado pensando que estou atrasado para o serviço em plena folga ou quando ouço um barulho acordo pensando ter um estranho na casa." (Soldado).

Quanto ao sono, deve-se destacar que foi possível observar uma relação entre um número baixo de horas de sono com um maior nível de estresse e tensão sentidos pelos entrevistados. Outro ponto que deve ser destacado está ligado ao intervalo de almoço. Dos entrevistados apenas 1 relatou realizar 1 hora de almoço, enquanto 6 afirmaram utilizar apenas 30 minutos, relatando que esse tempo ainda pode ser menor caso seja necessário, devido a alguma ocorrência ou emergência policial. 
“Já tive que parar de comer inúmeras vezes para atender chamado." (Cabo 1).

“(...) praticamente não temos hora para fazer uma refeição, como uma pessoa Civil.” (Sargento 2).

\subsection{Resultados da aplicação do RULA e análise do posto de trabalho}

Os postos de trabalho analisados no artigo foram divididos em dois grupos denominados de posto unidade 1 e posto unidade 2. No posto de unidade 1 é realizado o atendimento telefônico, transcrição de boletins de ocorrência e procedimentos padrões internos, como preenchimento de documentos. Este está representado na Figura 4.

Figura 4: Policial no posto de unidade 1

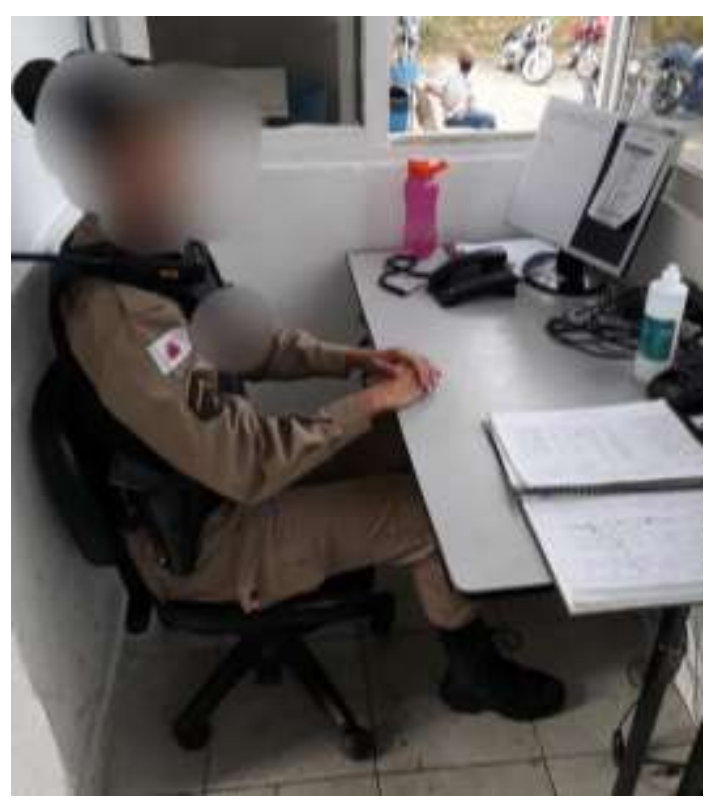

Fonte: Dados de pesquisa.

É possível perceber que a altura da mesa se encontra ligeiramente maior que a recomentada, possuindo $75 \mathrm{~cm}, 1 \mathrm{~cm}$ a mais que o recomendado por Iida (2005). Pode ser verificada também uma limitação quanto a cadeira, que além de não possuir apoio para os braços, possui uma limitação de movimentação devido ao espaço entre a mesa e a parede. A cadeira possui ajuste de altura, podendo ser regulada conforme o indivíduo. Não foi observado apoio para os pés, muito embora esse só seja necessário em casos de indivíduos de menor estatura. Outro ponto importante está relacionado ao tipo de telefone utilizado. Como pode ser verificado na imagem, esse é um modelo convencional, o qual não possui suporte de fixação, necessário para liberar as duas mãos durante o trabalho. Isso traz inconvenientes dada a necessidade de atender ao telefone e digitar de forma simultânea. Desta forma, é necessário que o trabalhador fixe o telefone ao corpo por meio da inclinação do pescoço, o que pode estar contribuindo para as dores na região cervical relatadas na entrevista.

No que cabe a análise pelo método RULA, pelo estudo do Grupo A, relativo aos membros superiores, é possível perceber que o braço da profissional se encontra em um ângulo entre $20^{\circ}$ a $45^{\circ}$ de flexão e o antebraço se enquadra em uma posição maior $100^{\circ}$ de flexão, o que representaria um total de 2 pontos cada um (Figura 13). Já os punhos encontram-se na posição neutra ou meia inclinação de pronação ou supinação. Assim, o total de pontos da posição corresponde a 3. No que cabe a análise dos membros inferiores, o método é direcionado ao posicionamento do pescoço, tronco, pernas e pés do trabalhador. É possível perceber na Figura 5 que o pescoço possui uma inclinação entre $0^{\circ} \mathrm{e} 10^{\circ}$, e que o tronco e as pernas que estão bem apoiados. Logo o total do grupo é de 1 ponto. 
Figura 5: Primeira posição destaque da análise RULA do posto unidade 1

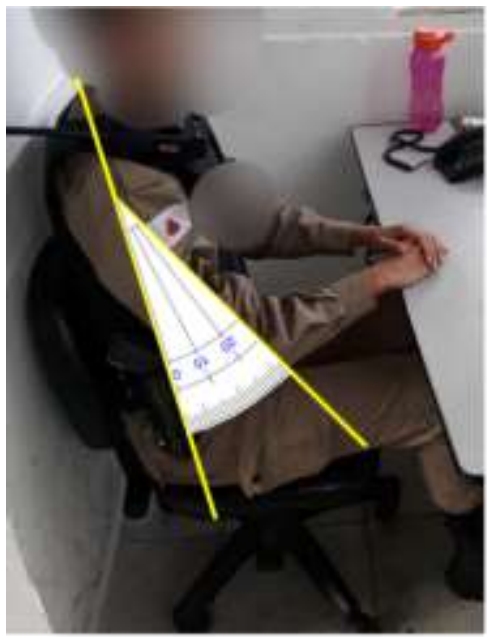

Braços

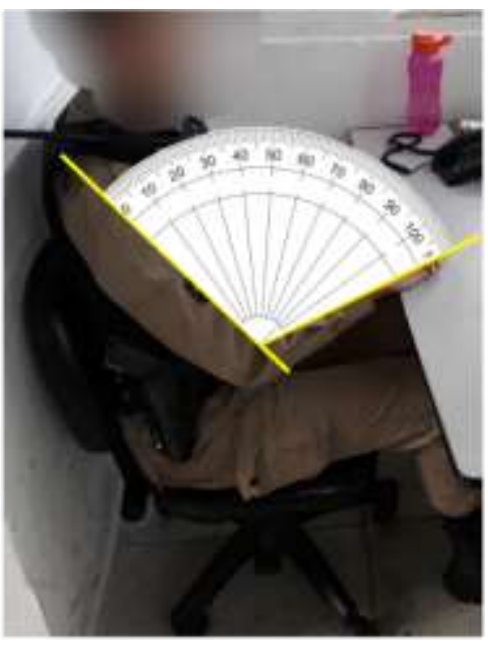

Antebraços

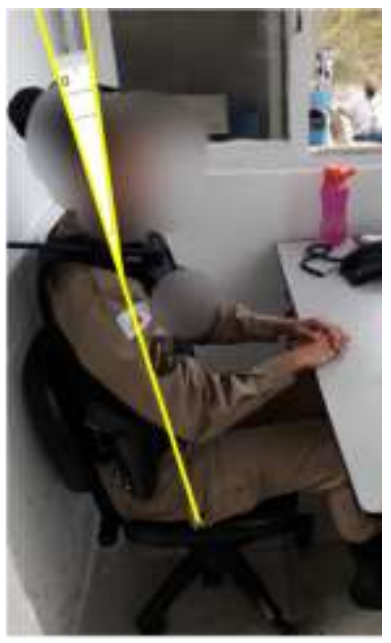

Pescoço

Fonte: Autores.

Como há uma postura com predominância estática por mais de 60 segundos e uma ação repetitiva por até 4 minutos, foi acrescido o valor de 1 ponto ao Grupo A e ao Grupo B. O Quadro 2 resume a pontuação aplicada a cada grupo. A combinação das pontuações de cada grupo resulta na pontuação final 3, indicando possíveis mudanças requeridas.

Quadro 2: Pontuação dos grupos A e B.

\begin{tabular}{|c|c|c|}
\hline Membro & Aplitude do Movimento & Pontos \\
\hline Braços & $20^{\circ}$ a $45^{\circ}$ de flexão & 2 \\
\cline { 1 - 2 } Antebraços & $0^{\circ}$ & 2 \\
\hline Punhos & de $<60^{\circ}$ de flexão ou $>100^{\circ}$ flexão & 1 \\
\hline Acrescimo & Predominância estática por mais de 60 segundos e uma ação repetitiva por até 4 minutos & 1 \\
\hline \multicolumn{2}{|c|}{ Total Dos Pontos Grupo A } & 4 \\
\hline Membro & Aplitude do Morimento & Pontos \\
\hline Pescoço & Entre 0 ${ }^{\circ}$ e $10^{\circ}$ de flexão & 1 \\
\hline Tronco & $0^{\circ}$ ou bem apoiado quando sentado & 1 \\
\hline Pernas & Pernas e pés bem apoiado & 1 \\
\hline Acrescimo & Predominância estática por mais de 60 segundos e uma ação repetitiva por até 4 minutos & 1 \\
\hline \multicolumn{2}{r|}{ Total Dos Pontos Grupo B } & $\mathbf{2}$ \\
\hline
\end{tabular}

Fonte: Autores.

Realizando a análise em outro posto da mesma unidade (Figura 6), os seguintes valores puderam ser observados. O tronco está com uma inclinação de $0^{\circ}$ a $20^{\circ}$, no qual é possível perceber que a distância do encosto da cadeira para o corpo da trabalhadora contribui para a postura não adequada. As pernas não se encontram apoiadas ou retas e o pescoço está com uma inclinação entre $10^{\circ}$ e $20^{\circ}$ de flexão. Já os braços estão com uma flexão entre $20^{\circ}$ e $45^{\circ}$, os antebraços entre $60^{\circ}$ e $100^{\circ}$ e os punhos entre $15^{\circ}$ e $-15^{\circ}$ de extensão. 
Figura 6: Destaques da segunda posição da análise RULA do posto da unidade 1.

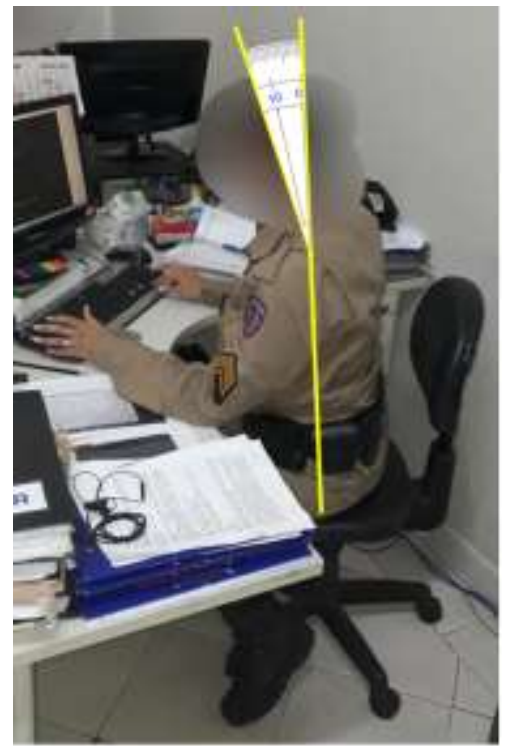

Pescoço

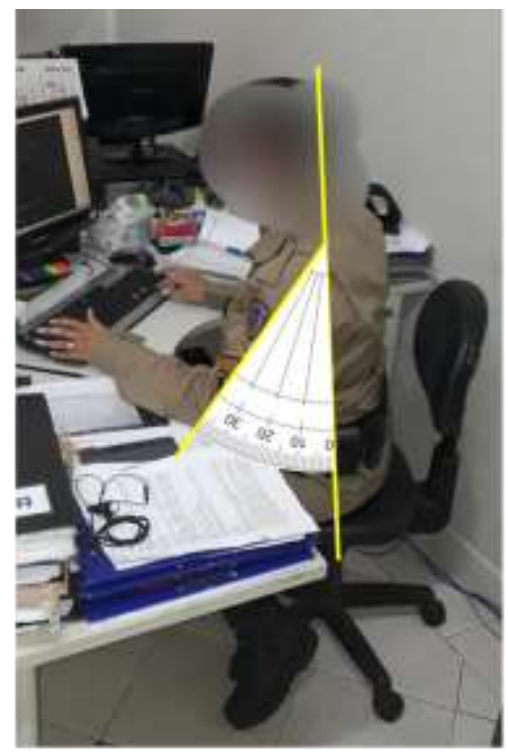

Braços

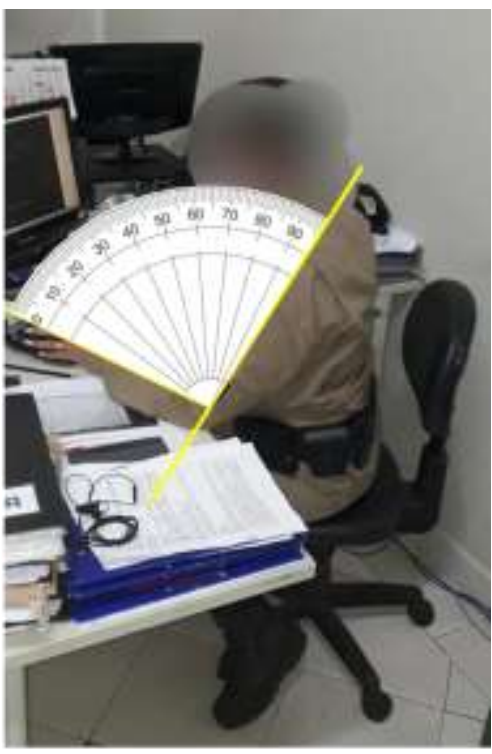

Antebraços

Fonte: Autores.

Assim, os membros do Grupo A atingiram 2 pontos na análise e os membros do Grupo B obtiveram 2 pontos cada um. Como no posto de trabalho anterior, neste posto é verificada a ação repetitiva por até 4 minutos, ampliando em 1 ponto o valor do Grupo A e do Grupo B, conforme o Quadro 3. A combinação das pontuações de cada grupo resulta na pontuação final 4 , indicando possíveis mudanças requeridas.

Quadro 3: Pontuação dos grupos A e B.

\begin{tabular}{|c|c|c|}
\hline Membro & Aplitude do Movimento & Pontos \\
\hline Braços & $20^{\circ}$ a $45^{\circ}$ de flexão & 2 \\
\hline Antebraços & de $<60^{\circ}$ de flexão ou $>100^{\circ}$ flexão & 2 \\
\hline Punhos & $15^{\circ}$ de flexão a $15^{\circ}$ de extensão & 2 \\
\hline Acrescimo & Predominância estática por mais de 60 segundos e uma ação repetitiva por até 4 minutos & 1 \\
\hline \multicolumn{2}{|c|}{ Total Dos Pontos Grupo A } & 4 \\
\hline Membro & Aplitude do Morimento & Pontos \\
\hline Pescoço & $0^{\circ}$ a $20^{\circ}$ de flexão & 2 \\
\hline Tronco & $0^{\circ}$ a 20 de flexão & 2 \\
\hline Pernas & Ao contrario & 2 \\
\hline Acrescimo & Predominância estática por mais de 60 segundos e uma ação repetitiva por até 4 minutos & 1 \\
\hline \multicolumn{2}{|c|}{ Total Dos Pontos Grupo B } & 4 \\
\hline
\end{tabular}

Fonte: Autores.

No que cabe aos postos de trabalho da unidade 2, estes são utilizados para o atendimento de policiais para averiguações, além de serem utilizados para as mesmas tarefas da unidade 1. Nota-se os mesmos problemas em relação ao mobiliário da unidade 1 , com limitação de movimentos, mesas com altura ligeiramente superior à recomendada e falta de apoio para os braços.

Quanto à análise RULA (Figura 7), no Grupo A foi verificada uma flexão nos braços entre $20^{\circ}$ e $45^{\circ}$, nos antebraços entre $60^{\circ}$ e $100^{\circ}$ e os punhos encontram-se em posição neutra. Já no tocante ao Grupo B, o pescoço possui uma flexão média entre $10^{\circ}$ e $20^{\circ}$. Já o tronco, uma inclinação entre $0^{\circ}$ e $20^{\circ}$ e as pernas e pés bem apoiados e equilibrados. 
Figura 7: Primeira posição destaque da análise RULA posto unidade 2.

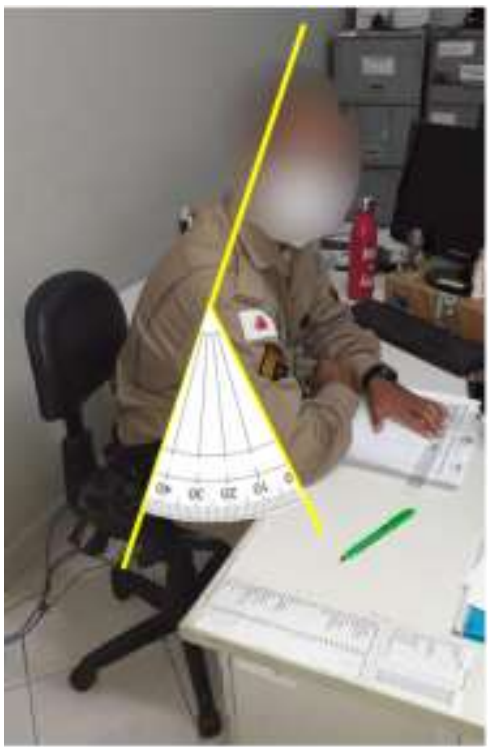

Braços

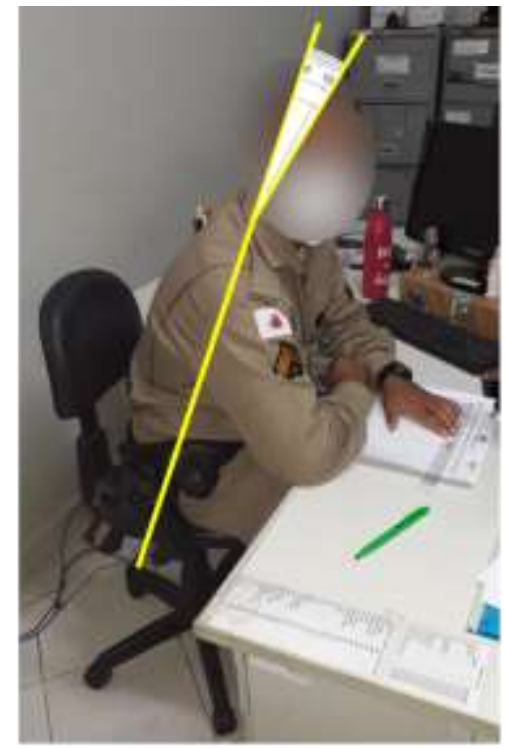

Pescoço

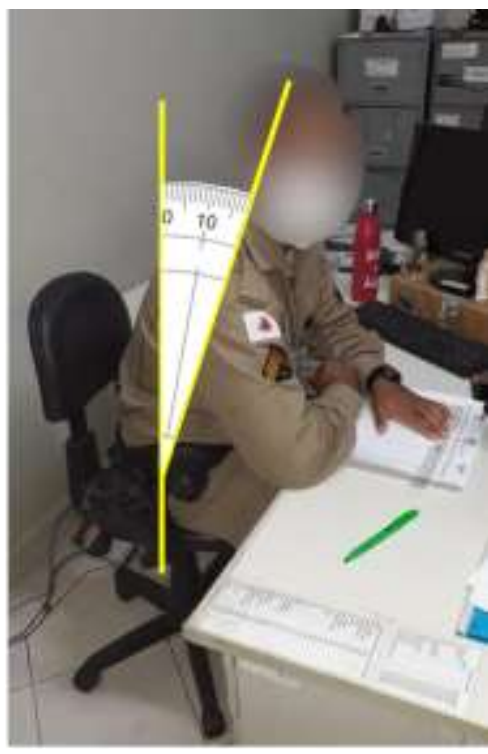

Antebraços

Fonte: Autores.

O valor de cada postura e o respectivo somatório de cada grupo estão representados no Quadro 4. A combinação das pontuações de cada grupo resulta na pontuação final 4 , indicando possíveis mudanças requeridas.

Quadro 4: Pontuação dos grupos A e B do primeiro posto de trabalho da unidade 2.

\begin{tabular}{|c|c|c|}
\hline Membro & Aplitude do Movimento & Pontos \\
\hline Braços & $20^{\circ}$ a $45^{\circ}$ de flexão & 2 \\
\hline Antebraços & de $<60^{\circ}$ de flexão ou $>100^{\circ}$ flexão & 2 \\
\hline Punhos & Predominância estática por mais de 60 segundos e uma ação repetitiva por até 4 minutos & 1 \\
\hline Acrescimo & Total Dos Pontos Grupo A & 4 \\
\hline \multicolumn{5}{|c|}{ Aplitude do Movimento } & Pontos \\
\hline Membro & $10^{\circ}$ a $20^{\circ}$ de flexão & 2 \\
\hline Pescoço & $0^{\circ}$ a $20^{\circ}$ de flexão & 2 \\
\hline Tronco & Pernas e pés bem apoiado & 1 \\
\hline Pernas & Predominância estática por mais de 60 segundos e uma ação repetitiva por até 4 minutos & 1 \\
\hline Acrescimo & Total Dos Pontos Grupo B & 4 \\
\hline \multicolumn{2}{|c|}{} \\
\hline
\end{tabular}

Fonte: Autores.

Quando analisado o segundo posto de trabalho da unidade 2, pode-se notar em concordância com a (Figura 8), que os braços e antebraços possuem uma flexão entre $20^{\circ}$ a $45^{\circ}$ e $60^{\circ}$ e $100^{\circ}$ respectivamente. Já quanto aos punhos os mesmos apresentam uma extensão e flexão superior a $15^{\circ}$. Em relação aos membros inferiores, o tronco está bem apoiado e o pescoço está com uma flexão entre $0^{\circ}$ e $10^{\circ}$, enquanto os pés e pernas estão flexionados sem estabilidade. 
Figura 8: Segunda posição destaque da análise RULA posto unidade 2.

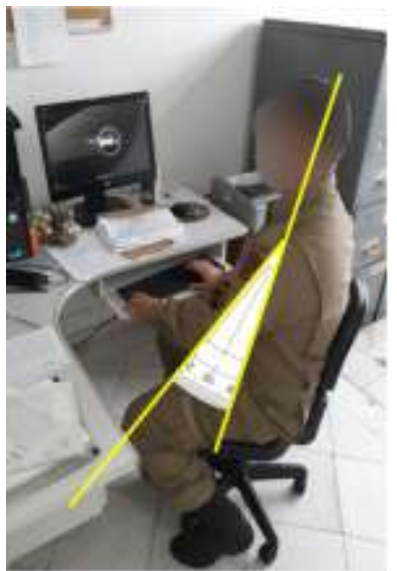

Braços

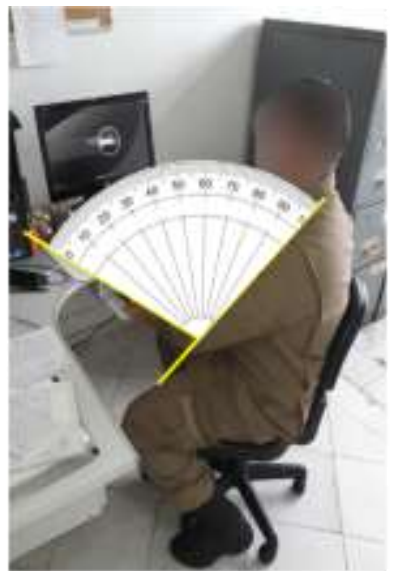

Antebraços

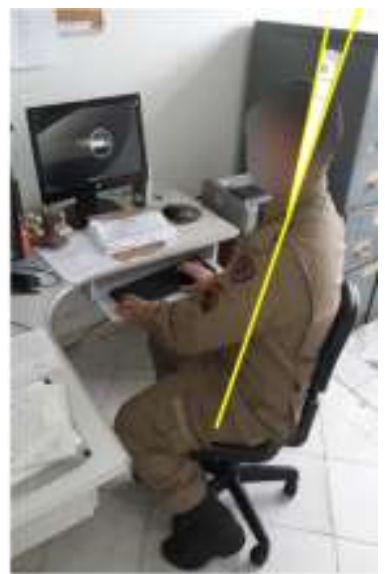

Pescoço

Fonte: Autores.

Os dados de pontuação obtidos para o posto de trabalho podem ser verificados no Quadro 5. A combinação das pontuações de cada grupo resulta na pontuação final 5 , indicando mudanças rápidas necessárias.

Quadro 5: Pontuação dos grupos A e B.

\begin{tabular}{|c|c|c|}
\hline Membro & Aplitude do Movimento & Pontos \\
\hline Braços & $20^{\circ} \mathrm{a} 45^{\circ}$ de flexão & 2 \\
\hline Antebraços & de $<60^{\circ}$ de flexão ou $>100^{\circ}$ flexão & 2 \\
\hline Punhos & Predominância estática por mais de 60 segundos e uma ação repetitiva por até 4 minutos & 3 \\
\hline Acrescimo & Total Dos Pontos Grupo A & 1 \\
\hline \multicolumn{2}{|c|}{ Aplitude do Movimento } & P \\
\hline Membro & $0^{\circ}$ a $10^{\circ}$ de flexão & 1 \\
\hline Pescoço & Bem apoiado & 1 \\
\hline Tronco & Pernas e pés ao contrário & 2 \\
\hline Pernas & Predominância estática por mais de 60 segundos e uma ação repetitiva por até 4 minutos & 1 \\
\hline Acrescimo & Total Dos Pontos Grupo B & 4 \\
\hline \multicolumn{2}{|c|}{} \\
\hline
\end{tabular}

Fonte: Autores

De acordo com os pontos analisados, apesar de alguns membros apresentarem pontuação mínima se analisados de forma individual, a soma dos grupos juntamente com o tempo na posição desperta a necessidade de cuidados e ressalvas nas atividades. Em especial visto o turno de trabalho e demais características das funções. Estes estão abordados nas discussões.

\subsection{Resultados da aplicação do Questionário Nórdico e análise do posto de trabalho}

A aplicação do questionário nórdico revelou dados importantes sobre os efeitos do ambiente e do trabalho sobre os policiais. Por meio dele foi possível verificar as principais áreas com presença de desconforto, incômodo ou dores durante os últimos 12 meses. As áreas do corpo apontadas podem ser visualizadas na Figura 9. 
Figura 9: Regularidade de desconforto por área no corpo nos últimos 12 meses

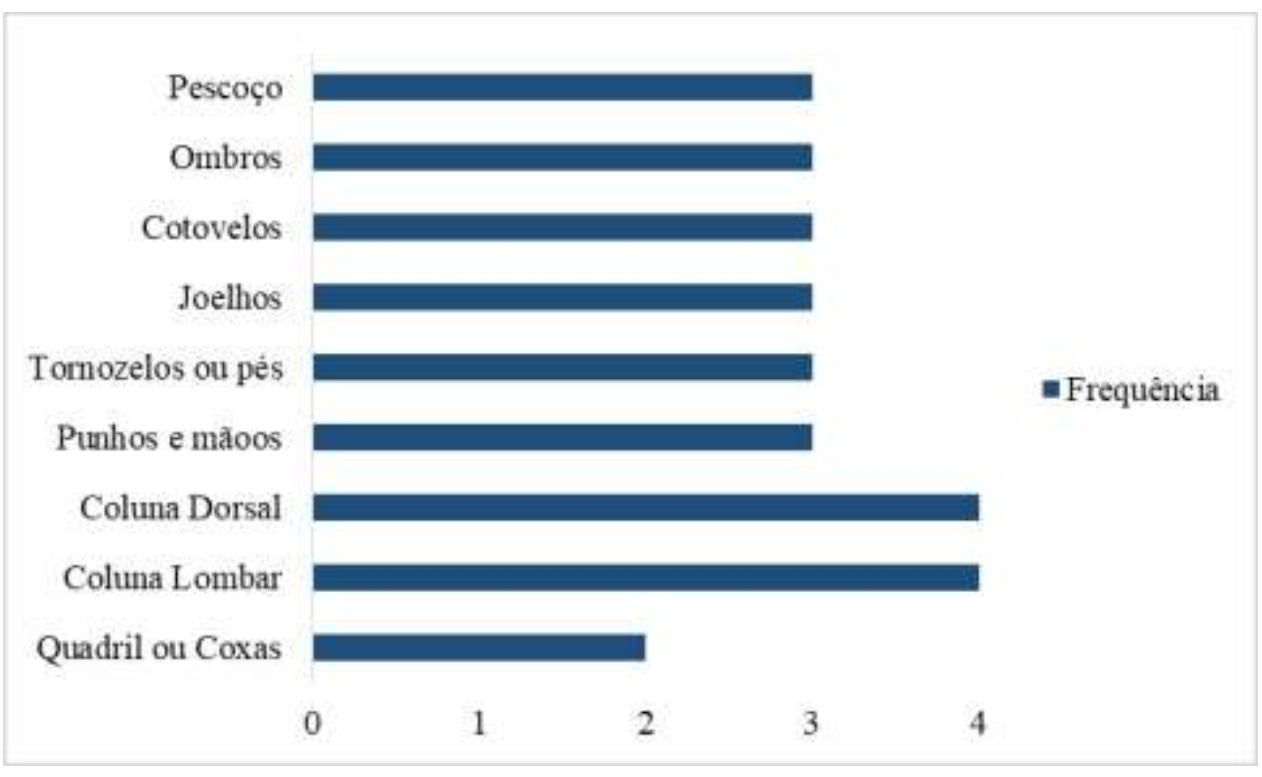

Fonte: Autores.

Percebe-se que as zonas com mais incômodo são a coluna lombar e dorsal, em que todos os entrevistados apontaram algum sintoma. Estas foram seguidas pelo pescoço, ombros, cotovelos, joelhos, tornozelos, pés, punhos e mãos, indicados por 3 dos 4 respondentes. Por fim, quadril ou coxas apareceu como incômodo para 2 respondentes. No que cabe ao pescoço, 3 de 4 dos respondentes apresentaram dores do lado esquerdo e apenas 1 do lado direito. Para o caso dos ombros, cotovelos, joelhos, tornozelos ou pés assim como punhos e mãos, a Figura 10 lista em qual dos lados do corpo os sintomas estão localizados.

Figura 10: Área de dor por região do corpo nos últimos 12 meses.

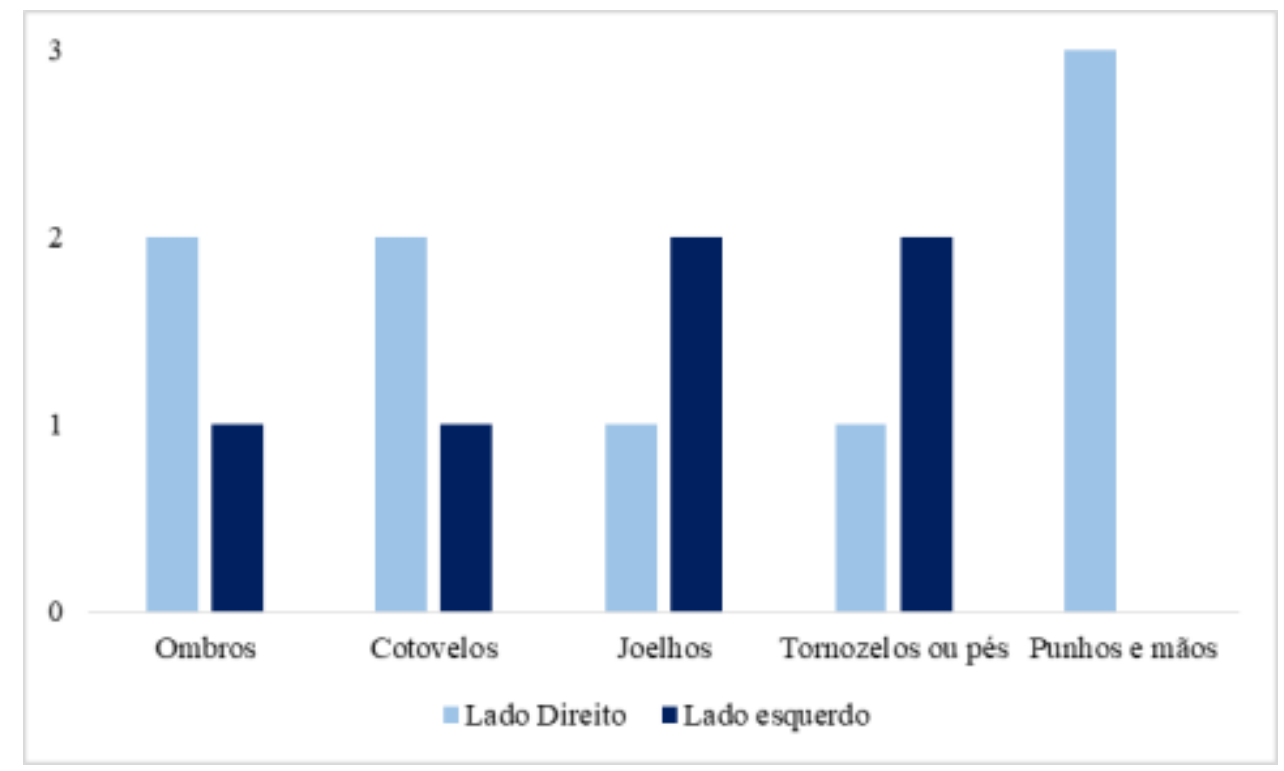

Fonte: Autores. 
É possível observar que, quando se refere aos membros inferiores, o lado esquerdo é o que possui maior relato de dor. Já quando se avaliam os membros superiores, o lado direito apresenta maiores índices. Vale ressaltar que nenhum dos respondentes foi afastado nos últimos 12 meses devido alguma dor ou desconforto.

Já no que cabe aos sintomas apresentados nos últimos 7 dias, é possível observar as regiões mais afetadas (Figura 11).

Figura 11: Regularidade de desconforto por área no corpo nos últimos 7 dias.

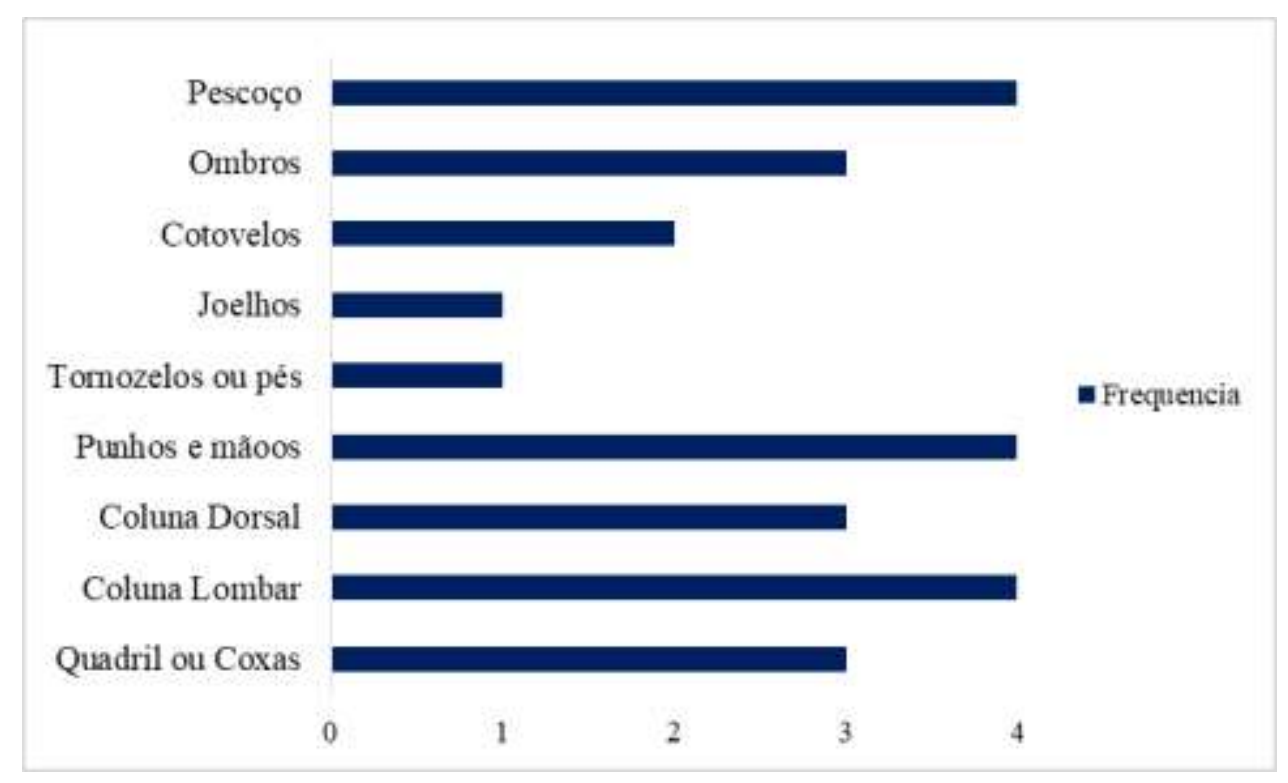

Fonte: Autores.

Nos últimos 7 dias antes da aplicação do questionário, as regiões relatadas como mais afetadas foram o pescoço, punhos, mãos e a coluna lombar; subsequentemente coluna dorsal, quadril e coxas. Os membros inferiores apresentam um menor número de relatos de dor. Tais prevalências podem estar ligadas a rotina dos policias e ao layout e disposição do ambiente de trabalho. Este pode ser verificado na Figura 12.

Figura 12: Posto de Trabalho.
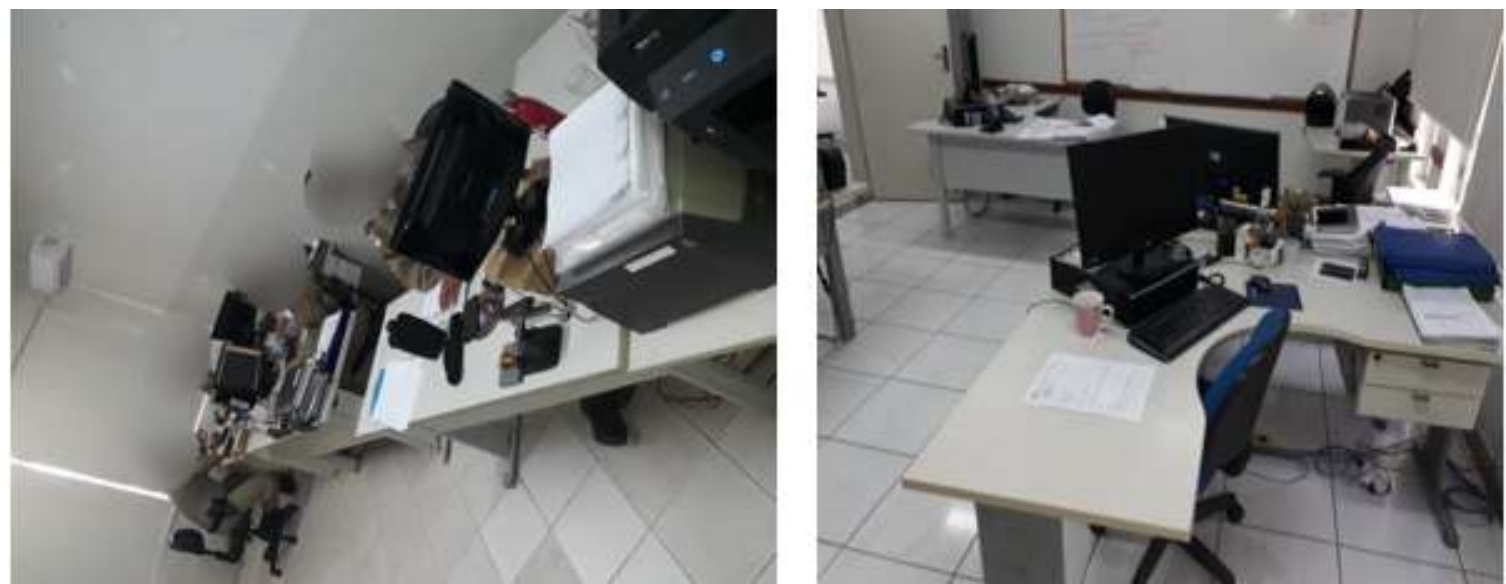

Fonte: Autores. 


\section{Discussão}

Com base nos resultados expostos, foi possível verificar a relação entre os aspectos psicológicos e exigências das tarefas (Iida, 2005) com a realidade das atividades exercidas pelos policiais, seus postos de trabalho e relatos de dores aferidas por meio do questionário nórdico. Essa relação reforça a necessidade de atenção especial a estes profissionais, dada a exposição a danos, tanto relacionados à saúde física quanto mental às quais estão sujeitos (Morais, 2010).

No que tange à ergonomia cognitiva, é possível perceber que as longas jornadas representam um problema generalizado na corporação. Embora essas atinjam em especial os policiais em operação, com uma alta carga psicológica associada (Maria, Santana, Freitas, Gomes \& Barbosa, 2019) as jornadas exaustivas não se restringem a eles, se estendendo também para o pessoal administrativo, conforme atestado nas entrevistas. Essa situação é agravada com a ausência de pausa ou de um tempo mínimo para a realização das refeições, quando da necessidade de atendimento de ocorrências.

A privação do sono também é um problema que deve ser considerado. As poucas horas de sono atreladas à alta periculosidade inerente à profissão (Silva \& Vieira, 2008), tem ação direta na percepção de estresse pelos policiais e na redução do bem estar.

Com relação aos postos de trabalho, as posturas analisadas por meio do método RULA apresentaram valores finais que variam entre 3 e 5, indicando a necessidade de mudanças e a necessidade de mudanças rápidas respectivamente. As mesas de trabalho em conjunto possuem medida de $145 \mathrm{~cm}$ de comprimento, por $60 \mathrm{~cm}$ de profundidade e $75 \mathrm{~cm}$ de altura fixa, já as mesas individuais dispõem de $135 \mathrm{~cm}$ de comprimento, por $70 \mathrm{~cm}$ de profundidade e $75 \mathrm{~cm}$ de altura fixa. Se comparadas à NR-17, não há problemas com a largura das mesas, porém, a profundidade encontra-se fora do padrão estabelecido (75cm mínimos). Já no caso da altura, conforme Iida (2005), no caso de mesas fixas o recomendado é de $74 \mathrm{~cm}$, com cadeira regulável e apoio para os pés onde aplicável. A altura da mesa, vinculada a uma má regulagem das cadeiras por parte dos policiais pode ser um dos fatores causadores de dores nos punhos, mãos e coluna.

Com relação à regulagem das cadeiras e os membros inferiores, foi possível notar problemas com o posicionamento baixo do assento, e inflexões na articulação do joelho. Assentos baixos prejudicam a estabilidade e permitem que o corpo deslize para frente, prejudicando a postura (Iida, 2005). Além disso, os assentos não são dotados de apoio para o cotovelo, conforme prevista na NR-17, o que pode ser uma das causas de dores nos ombros e cotovelos.

Outro ponto importante relacionado aos equipamentos está ligado aos telefones utilizados. Dores na região do pescoço e nos ombros podem estar associadas a falta de um aparelho telefônico adequado que permita o livre movimento das mãos para a digitação. A limitação dos membros devido à quantidade de material disponível em cima da mesa de trabalho também pode ser considerado um problema.

A análise dos resultados do RULA também deixou claro que nenhuma das posturas verificadas recebeu pontuação 1 ou 2. Isso significa que nenhuma delas deve ser mantida por longos períodos de tempo. Porém, deve-se ressaltar que o espaço existente entre a mesa e as paredes nem sempre permite uma boa movimentação dos policiais ao longo da jornada, explicitando a inadequação da disposição do mobiliário.

De forma a solucionar tais dissonâncias ergonômicas, uma série de propostas podem ser feitas no intuito de melhorar a relação dos policiais com o seu ambiente de trabalho. Uma dessas propostas diz respeito à redução da carga de estresse dos profissionais que trabalham nas operações, com o rodizio de policiais. Neste caso também deve-se destacar a necessidade de um acompanhamento e apoio psicológico por profissional especializado para evitar quadros extremos de estresse ou insônia.

Outra questão importante é a readequação do layout para melhor movimentação dos trabalhadores em seus postos de trabalho, principalmente nos casos em que a distância entre as mesas e paredes influencie na liberdade de movimentos. Além disso, sugere-se a troca ou adaptação de parte do mobiliário, o qual apresenta-se em dissonância com indicações ergonômicas, como no caso das mesas elevadas e cadeiras sem apoio para os braços. A ampliação do uso de armários pode ajudar a melhorar 
a organização e ampliar o espaço livre de trabalho nas mesas. Além disso, a troca de telefones convencionais por head-sets pode facilitar a atuação dos profissionais que fazem o registro dos boletins de ocorrência.

Porém, deve-se salientar que apenas a troca do mobiliário e equipamentos pode não ser suficiente. Desta forma, recomenda-se também a criação de um programa com recomendações ergonômicas para os policiais. Este programa deve visar a conscientização com relação às questões observadas que podem ser melhor tratadas, como postura adequada de trabalho, realização de pausas, estresse, entre outros temas. A utilização de ginastica laboral como forma de redução das dores e alivio das tensões também pode ser aplicada.

\section{Considerações Finais}

Este artigo teve como objetivo realizar uma análise ergonômica em um posto da polícia militar em Minas Gerais, no intuito de contribuir para a melhoria das condições de trabalho dos policiais. Para isso, foram aplicadas técnicas e ferramentas para levantar medidas adequadas ao tratamento de problemas relacionados à ergonomia física e cognitiva presentes. A partir dos dados obtidos, foi possível estabelecer um panorama das reais condições de vida e de trabalho dos policias militares do batalhão estudado, bem como os riscos e problemas relacionados às suas funções. Por meio da análise do método RULA em conjunto com o Questionário Nórdico Musculoesquelético e as entrevistas, ficaram evidentes os riscos e as consequências das tarefas desempenhadas pelos policiais, sobretudo no desenvolvimento de doenças laborais físicas e psicológicas

A prevalência de dores e incômodos no trabalho, em especial nos ombros, pescoço, coluna, punhos e mãos indicam uma origem comum relacionada a não adaptação do posto de trabalho, acrescidas das longas jornadas, mobiliário e equipamentos inadequados, assim como pausas reduzidas. Além disso, o ritmo intenso exigido pela organização corrobora com o aumento do estresse e fadiga dos profissionais, com destaque para aqueles que participam de operações práticas. Além disso, a instabilidade dos turnos e o risco físico iminente são favoráveis ao aumento da sensação de fadiga, desconforto, assim como riscos de doenças laborais.

Neste cenário, pôde-se traçar medidas importantes de forma a mitigar os efeitos negativos do trabalho dos policiais militares. São elas: o rodizio de profissionais em operações práticas e o acompanhamento e apoio psicológico; a alteração do layout de trabalho com foco no espaço de desenvolvimento das atividades administrativas e organização geral; a troca ou adaptação de mesas e cadeiras; a utilização de head-sets em substituição ao telefone convencional; e a criação de um programa de conscientização ergonômica, com inclusão de ginástica laboral. Cabe ressaltar que a aplicação das propostas de melhoria sem a dada continuidade ou incentivo a conscientização tendem a não serem efetivas.

Como limitação do estudo, deve-se ressaltar as restrições de circulação impostas pela COVID-19, o que fez com que o método abordado fosse executado por meio de entrevistas remotas e não presenciais como planejado inicialmente. Além disso, ressalta-se a utilização de apenas um posto da polícia militar, o que direciona os achados da pesquisa para o caso em si. Porém, neste aspecto, deve-se ressaltar que a consonância deste caso com outros estudados para o desenvolvimento do artigo, acaba por reforçar estes achados, dadas as condições de trabalho dos policiais militares no Brasil.

Por fim, como proposição de novos estudos, sugere-se a análise de alguns fatores ergonômicos importantes, que devido à delimitação abordada, acabaram por não fazer parte deste artigo. Dentre eles pode-se destacar a iluminação dos ambientes de trabalho e sua climatização, dado que esses fatores podem vir a afetar diretamente a percepção dos usuários quanto às suas tarefas. Outro estudo que pode ser desenvolvido diz respeito à própria reformulação do layout, por meio de uma análise detalhada dos espaços e suas condições. 


\section{Referências}

Abrantes, A. F. (2004). Atualidades em ergonomia-logística: movimentação de materiais, engenharia industrial, Escritórios. São Paulo: Editora IMAM.

Afonso, L., Pinho, M. E., \& Arezes, P.M. (2014). Risk factors associated with musculoskeletal symptoms in footwear sewing workers. In Occupational Safety and Hygiene II (pp. 611-616). CRC Press.

Alves, R. B. (2003). Vigilância em saúde do trabalhador e promoção da saúde: aproximações possíveis e desafios. Cadernos de Saúde Pública, 19 , 319-322.

Anchieta, V. C. C., Galinkin, A. L., Mendes, A. M. B., \& Neiva, E. R. (2011). Trabalho e riscos de adoecimento: um estudo entre policiais civis. Psicologia: Teoria e Pesquisa, 27, 199-208.

Associação Brasileira de Ergonomia. (2000). Certificação do ergonomista brasileiro. http://www.abergo.org.br/

Associação dos Praças Policiais e Bombeiros Militares de Minas Gerais. (2019). Afastamento de Policiais e Bombeiros Militares de Minas Gerias. http://aspra.org.br/site/index.php/

Barros, E. N. C., \& Alexandre, N. M. C. (2003). Cross-cultural adaptation of the Nordic musculoskeletal questionnaire. International nursing review, 50(2), $101-108$.

Barros, I. F. D. R. (1996). Fatores antropométricos e biomecânicos da segurança do trabalho: uma contribuição à análise de sistemas homem-máquina sob o ponto de vista da ergonomia. In Fatores antropométricos e biomecânicos da segurança do trabalho: uma contribuição à análise de sistemas homem-máquina sob o ponto de vista da ergonomia (pp. 122-122).

Baú, L. M. S. (2002). Fisioterapia do trabalho: ergonomia, legislação, reabilitação. Curitiba: Clãdosilva, 270.

Bitencout, R., Guimarães, L. D. M., \& Saurin, T. (2004). Fábrica da inclusão: a viabilidade de concepção de um sistema produtivo inclusivo. In Congresso Brasileiro de Ergonomia (Vol. 13).

Bouyer, G. C. (2007). A ciência ergonômica entre a epistemologização e a cientificidade. Encontro Nacional de Engenharia de Produção, 27.

Collis, J., \& Hussey, R. (2005). Pesquisa em administração: um guia prático para alunos de graduação e pós-graduação. Bookman.

Deimling, M. F., \& Pesamosca, D. (2014). Análise Ergonômica do Trabalho (AET) em uma empresa de confecções. Iberoamerican Journal of Industrial Engineering, 6(11), 37-58.

Brasil, C. F. (2010). Constituição da República Federativa do Brasil de 1988.

Do Rio, R. P., \& Pires, L. (2001). Ergonomia: fundamentos da prática ergonômica. LTr.

Ferrari, A. L. (2009). Adaptação transcultural do questionário cultural study of musculo-skeletal and other symptoms and associated disability CUPID Questionnaire. Tese de doutorado, Universidade de São Paulo, São Paulo, SP, Brasil.

Guérin, F., Kerguelen, A., \& Laville, A. (2001). Compreender o trabalho para transformá-lo: a prática da ergonomia. Editora Blucher.

Iida, I. (2005). Ergonomia: projeto e produção. Editora Blucher.

Junnior, R. C. D., Silva, B. C. B., Canedo, G. R. (2017). Aplicação do Método Rula (Rapid Upper Limb Assement) em laboratório didático. XXXVII Encontro Nacional de Engenharia de Produção: A Engenharia de Produção e as novas tecnologias produtivas: indústria 4.0, manufatura aditiva e outras abordagens avançadas de produção. http://www.abepro.org.br/biblioteca/TN_STO_241_401_32996.pdf.

Lemos, L. C. (2009). Prevalência de queixas de dores osteomusculares em motoristas de caminhão que trabalham em turnos irregulares. Tese de doutorado, Universidade de São Paulo, São Paulo, SP, Brasil.

Lueder, R. A. (1996). Proposed RULA for Computer Users Proccedings of the Ergonomics Summer Workshop, the UC Berkeley Center for Occupational Environmental Health Continuing \& Program. San Francisco

Maria, L. H., Santana, P.V., Freitas, D. R., Gomes, V. M.C., \& Barbosa, L. C. M. (2019). Análise ergonômica do setor operacional e administrativo de um posto de trabalho da Polícia Militar. XXXIX Encontro Nacional de Engenharia de Produção: Os desafios da engenharia de produção para uma gestão inovadora da 40 Logística e Operações, 2019. http://www.abepro.org.br/biblioteca/TN_STP_000_1677_37858.pdf

Mascia, F. L.; Sznelwar, L. I.(1997). Ergonomia. In: CELSO, J. Contador. São Paulo: Edgard Blücher

Mateus Junior, J. R. (2009). Diretrizes para uso das ferramentas de avaliação de carga física de trabalho em ergonomia: equação NIOSH e protocolo RULA. Dissertação de mestrado, Universidade Federal de Santa Catarina, Florianópolis, SC, Brasil.

McAtamney, L., \& Corlett, E. N. (1993). RULA: a survey method for the investigation of work-related upper limb disorders. Applied ergonomics, 24(2), 9199.

Michel, O. (2000). Acidentes do trabalho e doenças ocupacionais. LTr.

Ministério da Justiça. (2019). Anuário Brasileiro de Segurança Pública. Fórum Brasileiro de Segurança Pública. Brasília, DF: Ministério da Justiça.

Minayo, M. C. (2002). Pesquisa social: teoria e método. Vozes.

Minayo, M. C. D. S., \& Adorno, S. (2013). Risco e (in) segurança na missão policial. Ciência \& saúde coletiva, $18(3), 585-593$. 
Research, Society and Development, v. 10, n. 10, e102101018688, 2021

(CC BY 4.0) | ISSN 2525-3409 | DOI: http://dx.doi.org/10.33448/rsd-v10i10.18688

Minicucci, A. (1995). Psicologia aplicada à administração. Atlas.

Morais, L. L. P. D., \& Paula, A. P. P. D. (2010). Identificação ou resistência? Uma análise da constituição subjetiva do policial. Revista de administração contemporânea, 14, 633-650.

Oliveira, G. R., \& Mont'Alvão, C. R. (2015). Metodologias utilizadas nos estudos de ergonomia do ambiente construído e uma proposta de modelagem para projetos de design de interiores. Estudos em Design, 23(3), 150-165.

Oliveira, M. T., \& Oliveira, A. P. (2020). A ergonomia na indústria da cerâmica: Uma avaliação ergonômica em trabalhadores. Research, Society and Development, 9(12), e25291210971-e25291210971.

Pinheiro, F. A., Tróccoli, B. T., \& Carvalho, C. V. D. (2002). Validação do Questionário Nórdico de Sintomas Osteomusculares como medida de morbidade. Revista de Saúde Pública, 36, 307-312.

Prüfer, C., Pereira, H., Arezes, P. M., Neves, A., Loureiro, M., Soares, P., ... \& Amaral, F. G. (2013). Continuous training in loco: Effects on the symptomatology of WRMD. Pedro M. Arezes; João Santos Baptista; Mónica P. Barroso; Paula Carneiro, 167-171.

Rangel, H.(2010). Portal da prevenção. http://portalprevencao.blo-gspot.com.br/.

Ranney, D. (2000). Distúrbios osteomusculares crônicos relacionados ao trabalho. Roca.

Rodriguez Añez, C. R. (2003). Sistema de avaliação para a promoção e gestão do estilo de vida saudável e da aptidão física relacionada à saúde de policiais militares. Tese de doutorado, Universidade Federal de Santa Catarina, Florianópolis, SC, Brasil.

Sampaio, K. R. A., \& Batista, V. (2021). Análise Ergonômica do Trabalho (AET) no ambiente de escritório: Um estudo de caso em uma empresa na cidade de Manaus-AM. Research, Society and Development, 10(7), e53110716478-e53110716478.

Santos, E. F., \& Santos, G. F. (2006). Análise de riscos ergonômicos. Ergo Brasil.

Santos, M. M. A., Souza, E. L. D., \& Barroso, B. I. D. L. (2017). Análise sobre a percepção de policiais militares sobre o conforto do colete balístico. Fisioterapia e Pesquisa, 24, 157-162.

Santos, N., \& Fialho, I. F. (1997). Manual de Análise Ergonômica do Trabalho. Genesis.

Shida, G. J., \& Bento, P. E. G. (2012). Métodos e ferramentas ergonômicas que auxiliam na análise de situações de trabalho. In VIII Congresso Nacional de Excelência em gestão.

Silva, M. B. D., \& Vieira, S. B. (2008). O processo de trabalho do militar estadual e a saúde mental. Saúde e sociedade, 17, 161-170.

Silveira, J.S., Cezar-Vaz, M. R., \& Xavier, D. M. (2020). Análise ergonômica e de alterações osteomusculares em trabalhadores: revisão integrativa. Research, Society and Development, 9(11), e349119500-e349119500.

Stanton, N.A., Hedge, A., Brookhuis, K., Salas, E., \& Hendrick, H.W. (2004). Manual de fatores humanos e métodos de ergonomia. CRC press.

VidalI, M. C. R. (2002). Ergonomia na empresa: útil, prática e aplicada. Virtual Científica.

VIieira, J. (2014). Manual de ergonomia. Manual de Aplicação da NR-17 (conforme publicação oficial do ministério do trabalho). Edipro.

Wisner, A. (1987). Por dentro do trabalho: ergonomia, método e técnica. In Por dentro do trabalho: ergonomia, método e técnica (pp. 189-189)

Yin, R. K. (2015). Estudo de Caso-: Planejamento e métodos. Bookman editora. 